OPEN ACCESS

Edited by:

Learn-Han Lee,

Monash University Malaysia, Malaysia

Reviewed by:

Aleš Svatoš,

Max-Planck-Institut für Chemische

Ökologie, Germany

Alejandra Prieto-Davó,

Universidad Nacional Autónoma

de México, Mexico

*Correspondence:

Usama R. Abdelmohsen usama.ramadan@mu.edu.eg

Tobias A. Oelschlaeger

t.oelschlaeger@uni-wuerzburg.de

Specialty section:

This article was submitted to Antimicrobials, Resistance

and Chemotherapy,

a section of the journal

Frontiers in Microbiology

Received: 04 April 2018

Accepted: 13 June 2018

Published: 11 July 2018

Citation:

Balasubramanian S, Skaf J, Holzgrabe U, Bharti R, Förstner KU,

Ziebuhr W, Humeida UH,

Abdelmohsen UR and

Oelschlaeger TA (2018) A New

Bioactive Compound From the Marine

Sponge-Derived Streptomyces sp.

SBT348 Inhibits Staphylococcal

Growth and Biofilm Formation.

Front. Microbiol. 9:1473.

doi: 10.3389/fmicb.2018.01473

\section{A New Bioactive Compound From the Marine Sponge-Derived Streptomyces sp. SBT348 Inhibits Staphylococcal Growth and Biofilm Formation}

\author{
Srikkanth Balasubramanian', Joseph Skaf ${ }^{2}$, Ulrike Holzgrabe², Richa Bharti ${ }^{3}$, \\ Konrad U. Förstner ${ }^{3}$, Wilma Ziebuhr ${ }^{1}$, Ute H. Humeida ${ }^{4}$, Usama R. Abdelmohsen ${ }^{5 *}$ and \\ Tobias A. Oelschlaeger ${ }^{\text {* }}$
}

\begin{abstract}
${ }^{1}$ Institute for Molecular Infection Biology, University of Würzburg, Würzburg, Germany, ${ }^{2}$ Institute of Pharmacy and Food Chemistry, University of Würzburg, Würzburg, Germany, ${ }^{3}$ Core Unit Systems Medicine, University of Würzburg, Würzburg, Germany, ${ }^{4}$ GEOMAR Helmholtz Centre for Ocean Research, RD3 Marine Microbiology, Christian-Albrechts-University of
\end{abstract} Kiel, Kiel, Germany, ${ }^{5}$ Department of Pharmacognosy, Faculty of Pharmacy, Minia University, Minia, Egypt

Staphylococcus epidermidis, the common inhabitant of human skin and mucosal surfaces has emerged as an important pathogen in patients carrying surgical implants and medical devices. Entering the body via surgical sites and colonizing the medical devices through formation of multi-layered biofilms leads to refractory and persistent device-related infections (DRIs). Staphylococci organized in biofilms are more tolerant to antibiotics and immune responses, and thus are difficult-to-treat. The consequent morbidity and mortality, and economic losses in health care systems has strongly necessitated the need for development of new anti-bacterial and anti-biofilm-based therapeutics. In this study, we describe the biological activity of a marine sponge-derived Streptomyces sp. SBT348 extract in restraining staphylococcal growth and biofilm formation on polystyrene, glass, medically relevant titan metal, and silicone surfaces. A bioassay-guided fractionation was performed to isolate the active compound (SKC3) from the crude SBT348 extract. Our results demonstrated that SKC3 effectively inhibits the growth (MIC: $31.25 \mu \mathrm{g} / \mathrm{ml}$ ) and biofilm formation (sub-MIC range: $1.95-$ $<31.25 \mu \mathrm{g} / \mathrm{ml}$ ) of S. epidermidis RP62A in vitro. Chemical characterization of SKC3 by heat and enzyme treatments, and mass spectrometry (HRMS) revealed its heat-stable and non-proteinaceous nature, and high molecular weight (1258.3 Da). Cytotoxicity profiling of SKC3 in vitro on mouse fibroblast (NIH/3T3) and macrophage (J774.1) cell lines, and in vivo on the greater wax moth larvae Galleria mellonella revealed its nontoxic nature at the effective dose. Transcriptome analysis of SKC3 treated S. epidermidis RP62A has further unmasked its negative effect on central metabolism such as carbon flux as well as, amino acid, lipid, and energy metabolism. Taken together, these findings suggest a potential of SKC3 as a putative drug to prevent staphylococcal DRIs.

Keywords: marine sponges, Streptomyces, Staphylococci, device-related infections, bioassay-guided fractionation, transcriptome 


\section{INTRODUCTION}

Surgical implants and medical devices have greatly assisted in improving the survival and recovery of patients from physical ailments (Vinh and Embil, 2005). However, they also are ideal niches for colonization and biofilm formation by microorganisms from patient's own skin, healthcare workers' skin, or hospitalized settings (Percival et al., 2015). Biofilms are networks of microorganisms that are entrapped in a selfproduced gluey matrix made up of polysaccharides, proteins, lipids, and eDNA (Otto, 2009; Flemming and Wingender, 2010). Microbes in biofilms exhibit 10-1000-fold increased resistance to antibiotics and host immune systems; and a number of mechanisms are supposed to contribute to this phenomenon such as the presence of biofilm matrix itself, slow growth rate and persister cell formation, efflux pumps, plasmid exchange, target mutations, and antibiotic-modifying enzymes etc. (Stewart and Costerton, 2001; Hall-Stoodley et al., 2004; Percival et al., 2011; Rajput et al., 2018). Current treatment of biofilm based device-related infections (DRIs) involves complete removal of the infected implant or device by a surgical procedure followed by prolonged antibiotic treatments (Otto, 2012). Biofilm based infections thus, lead to increased patient morbidity and mortality, and increased health care costs (Shida et al., 2013; Kleinschmidt et al., 2015; Leary et al., 2017).

The majority of the DRIs reported till date are a consequence of biofilm formation by coagulase negative (e.g., Staphylococcus epidermidis) and positive (e.g., S. aureus) staphylococci (Mack et al., 2007; Becker et al., 2014; Windolf et al., 2014). Predominantly, S. epidermidis an inhabitant of skin and mucosa is the leading cause of nosocomial and DRIs (Otto, 2009; Franca et al., 2012; Namvar et al., 2014; Sabate Bresco et al., 2017). The development of complications like catheter-related blood stream infections, prosthetic joint infections, early onset neonatal sepsis etc., and the rapid emergence of drug-resistant staphylococcal strains in hospital and community settings has challenged the effectiveness of current therapeutic regimes (Barros et al., 2014; WHO, 2014; Sakimura et al., 2015; Widerstrom, 2016). Therefore, it is imperative to develop novel antibacterial and anti-biofilm-based therapeutics for management of the hard-to-treat staphylococcal infections (Bjarnsholt et al., 2013).

Marine bioprospecting has gained much attention in the recent years owing to its massive chemical and biological diversity (Mayer et al., 2010; Gerwick and Moore, 2012; Martins et al., 2014; Thompson et al., 2017). A variety of bioprospecting techniques (including cultivation-dependent to independent approaches) have been described so far towards harnessing the bioactive potential of the marine realm (Abdelmohsen et al., 2015; Kodzius and Gojobori, 2015; Indraningrat et al., 2016). Particularly, marine sponges and their associated actinomycetes are abundant reserves of novel natural products with distinct biological activities of pharmaceutical importance (Thibane et al., 2010; Abdelmohsen et al., 2014a, 2015, 2017). A wide spectrum of anti-staphylococcal compounds and extracts possessing antibacterial and/or anti-biofilm activities have been reported from marine sponges and microbes (Rahman et al., 2010; Stowe et al., 2011; Beau et al., 2012; Palomo et al., 2013; Gomes et al., 2014; Balasubramanian et al., 2017).

A preliminary anti-biofilm screening (against the model isolate S. epidermidis RP62A) with 50 different organic extracts obtained from solid and liquid batch fermentations of 25 different marine sponge-derived actinomycetes, led to the identification of the bioactive extract from Streptomyces sp. SBT348. Marine sponge-derived Streptomyces sp. SBT348 is a Gram-positive bacterium that was previously shown to possess distinct metabolomic and rich chemistry profiles with strong biological activities (Cheng et al., 2015, 2017). In this study, bioassay-guided fractionation was performed to unravel the active component(s) in the SBT348 extract. The most active compound SKC3 was evaluated further for growth and biofilm inhibition on various S. epidermidis, S. aureus, and Pseudomonas aeruginosa strains. Results obtained highlighted the specific anti-biofilm nature of SKC3 with high potency and nontoxic nature. Chemical analysis revealed the heat-stable, nonproteinaceous, and high-molecular weight of SKC3 (1258.3 Da). Finally, data from transcriptome analysis revealed the regulation of expression of several genes related to carbon, amino-acid, proteins, lipids, nucleotides, and energy metabolism suggesting the possible interference of SKC3 with global metabolism of staphylococci.

\section{MATERIALS AND METHODS}

\section{Instrumentation}

Flash chromatography was done on an Interchim Puri-Flash 430 instrument (ultra performance flash purification) connected to an Interchim flash ELSD (Montlucon, France).

Semi-preparative HPLC of the active fraction was perfomed with Agilent 1100 series (Waldbronn, Germany) using GeminiNX5u-C18-110A column $(250 \times 10 \mathrm{~mm}$, Phenomenex, United States) and detection at $250 \mathrm{~nm}$. The following gradient was applied solvent A: water and solvent B: acetonitrile. Separation method: solvent B $20 \%$ for $4 \mathrm{~min}, 40 \%$ for $11 \mathrm{~min}$, 40 to $50 \%$ in $5 \mathrm{~min}, 50$ to $90 \%$ in $1 \mathrm{~min}$, and again to $20 \%$ in $4 \mathrm{~min}$; maximum pressure of 400 bar and a flow rate of $4 \mathrm{ml} / \mathrm{min}$.

Purity of the compound was determined with analytical HPLC system but with Gemini-NX5u-C18-110A column $(250 \times 4.60 \mathrm{~mm}$, Phenomenex, United States). Separation method: solvent B $5 \%$ at $0 \mathrm{~min}, 5$ to $100 \%$ for $25 \mathrm{~min}, 100 \%$ for $1 \mathrm{~min}, 100$ to $50 \%$ in $2 \mathrm{~min}$, and again to $5 \%$ in $2 \mathrm{~min}$; maximum pressure of $400 \mathrm{bar}$; flow rate of $1 \mathrm{ml} / \mathrm{min}$; wavelength of $250 \mathrm{~nm}$.

Fourier transform-infrared spectroscopy (FT-IR) of SKC3 were conducted using Jasco FT/IR-6100 spectrometer with an ATR unit (Groß-Umstadt, Germany) at room temperature.

Mass spectrometry measurements were performed using normal electrospray ionization (ESI; in positive mode) in a micrOTOF-QIII mass spectrometer (Bruker Daltonics, Billerica, MA, United States) coupled to an Agilent 1100 HPLC system. ESI was operated with a capillary voltage of $4.5 \mathrm{KV}$. Nitrogen at $200^{\circ} \mathrm{C}$ and a flow rate of $7 \mathrm{l} / \mathrm{min}$ was used as the desolvation gas. Mass spectral data was obtained over a range of $50-3500 \mathrm{~m} / \mathrm{z}$. 
Scanning electron microscopy (SEM) was done with JEOLJSM-7500F (Japan) with field emission gun system.

\section{Bacterial Strains and Culture Conditions}

Bacterial strains used in the work are mentioned in Table 1. Streptomyces sp. SBT348 was grown in ISP2 medium $(4 \mathrm{~g} / \mathrm{l}$ yeast extract, $10 \mathrm{~g} / \mathrm{l}$ malt extract, and $4 \mathrm{~g} / \mathrm{l}$ glucose in artificial sea water) at $30^{\circ} \mathrm{C}$. All other strains in the study were cultured in Tryptic Soy Broth (TSB; Becton Dickinson) (17.0 g/l pancreatic digest of casein, $3.0 \mathrm{~g} / \mathrm{l}$ peptic digest of soybean meal, $5.0 \mathrm{~g} / \mathrm{l}$ sodium chloride, $2.5 \mathrm{~g} / \mathrm{l}$ dipotassium hydrogen phosphate, and $2.5 \mathrm{~g} / \mathrm{l}$ glucose) and incubated at $37^{\circ} \mathrm{C}$.

\section{Large Scale Fermentation and Extract Preparation}

A total of 1,000 ISP2 agar plates (prepared with artificial sea water) were inoculated with a week-old liquid culture of Streptomyces sp. SBT348, respectively, and were incubated at $30^{\circ} \mathrm{C}$ for $10 \mathrm{~d}$ (batch fermentation). Agar with bacterial biomass was cut into small pieces and transferred into 11 of ethyl acetate. The solutions were subjected to shaking at $175 \mathrm{rpm}$ in a shaker overnight. Subsequently, the macerations were filtered, and the filtrates were evaporated in vacuo to obtain the dried SBT348 organic extract. Agar plates without the actinomycetes were extracted in a similar manner and this was the medium control for the bioactivity testing. Extracts were dissolved in DMSO (final concentration $3.75 \% \mathrm{v} / \mathrm{v}$ ) and used for in vitro assays. Additionally, SEM was done for the Streptomyces sp. SBT348 10th day culture on the ISP2 agar plate. The SEM protocol has been described below.

\section{Bioassay Guided-Fractionation for Isolation for Active Component(s)}

A total of $1.2 \mathrm{~g}$ of the dried extract obtained was subjected to fractionation using a flash chromatography with a cyclohexane/ethyl acetate/methanol gradient eluent, yielding 10 major fractions. After biological evaluation of each major fraction in vitro, against the biofilm formation of S. epidermidis RP62A, the active fraction Fr 7 was found. Fr 7 was subfractionated by semi-preparative HPLC and this yielded seven sub-fractions (including the bioactive SKC1, SKC2, SKC3, SKC4, and SK7). The bioactive fraction was further purified on HPLC to yield the bioactive compound SKC3. Pure compound SKC3 was dissolved in DMSO (final concentration 3.75\% on cells) or stored dry in amber colored vials at $-80^{\circ} \mathrm{C}$ to ensure stability.

\section{Characterization of the Active Compound SKC3 \\ Stability of Compound to Heat and Enzyme Treatments}

SKC3 at the respective effective concentrations was subjected to heat $\left(100^{\circ} \mathrm{C}\right.$ for $1^{\circ} \mathrm{h}$; followed by cooling on ice) and enzymatic (proteinase $\mathrm{K}$ and trypsin; final concentration of $1 \mathrm{mg} / \mathrm{ml}, 37^{\circ} \mathrm{C}$ for $1 \mathrm{~h}$ ) treatments. As controls, DMSO (final concentration of $3.75 \%)$ was subjected to similar heat and enzymatic treatments.
For each of the treatments, the growth and biofilm inhibitory effects of treated and untreated SKC3 were assessed using the microtiter 96-well plate assay against S. epidermidis RP62A. Each data point is composed of three independent cultures performed in duplicates.

\section{Biofilm Assay and MIC Determination}

Biofilm assay was perfomed as previously described (Balasubramanian et al., 2017). Bacterial strains $\left(\mathrm{OD}_{600} \sim 0.05\right.$ in TSB) were incubated in the presence of SBT348 extract or SKC3 at different concentrations at $37^{\circ} \mathrm{C}$ (for S. epidermidis and P. aeruginosa) or $30^{\circ} \mathrm{C}$ (for $S$. aureus) for $24 \mathrm{~h}$. Experimental controls included bacteria treated with ISP2 medium extract or DMSO and TSB without bacteria. MIC was determined against the various pathogenic bacterial strains in this microbroth dilution assay according to CLSI protocols. $\mathrm{OD}_{630}$ values were used to determine the MICs. MIC was determined as the concentration of the test substance where the lowest $\mathrm{OD}_{630}$ values were recorded with no visible bacterial growth. After $\mathrm{OD}_{630}$ measurement, the planktonic bacteria were discared by rinsing with sterile $1 \times$ PBS (sterile) and biofilm cells were heat fixed at $65^{\circ} \mathrm{C}$ for $1 \mathrm{~h}$. Plates were then stained with $0.3 \%$ crystal violet for $5 \mathrm{~min}$, washed thrice with sterile double-distilled water and air-dried briefly. Finally, $\mathrm{OD}_{492}$ measurements determined the extent of biofilm inhibition in test wells in comparison with control. S. epidermidis (ATCC12228) and S. carnosus TM300 were the biofilm negative strains used in the experiment.

For studying the effect on existing or pre-formed biofilms, biofilms were established shortly before the experiment with the above protocol. Formed biofilms were then treated with fresh TSB (control) or the test substance at their respective final concentrations and incubated further at $37^{\circ} \mathrm{C}$ or $30^{\circ} \mathrm{C}$ for $24 \mathrm{~h}$. The extent of biofilm eradication was assessed with the crystal violet assay. $\mathrm{NaIO}_{4}$ that digests the biofilm matrix (polysaccharides) was used as the positive control in the experiment.

\section{Growth Curve Studies}

The antagonistic effect of SBT348 extract and SKC3 on the growth of S. epidermidis RP62A was determined by growth curve measurements (Nithya et al., 2010). Briefly, SBT348 extract or SKC3 (MIC and $\mathrm{MBIC}_{90}$ ) were added to tubes containing bacteria (initial $\mathrm{OD}_{600}$ of 0.1 ). Tubes were incubated at $37^{\circ} \mathrm{C}$ at $200 \mathrm{rpm}$. Bacterial growth was monitored for every $2 \mathrm{~h}$ up to $24 \mathrm{~h}$ by optical density and CFU measurements (every $4 \mathrm{~h}$ ). TSB medium devoid of the bacteria was used as the negative control while medium extract or DMSO treated bacteria served as the appropriate controls in the experiment. Three independent cultures were used in this experiment to ensure reproducibility of results.

\section{Anti-biofilm Effect on Different Surfaces}

The anti-biofilm effect of SBT348 extract and the compound SKC3 was studied at their respective BICs on different surfaces; glass cover slips (diameter of $12 \mathrm{~mm}$ ), medically relevant titan metal plates (diameter of $1.5 \mathrm{~cm}$; University clinic for dental, oral and jaw diseases, Würzburg, Germany), and silicone 
TABLE 1 | Strains used in this study.

\begin{tabular}{|c|c|c|c|}
\hline Strain & Origin & Relevant characteristics & Reference and/or source \\
\hline Streptomyces sp. SBT348 & $\begin{array}{l}\text { Marine sponge-derived actinomycetes } \\
\text { strain\# }^{\#}\end{array}$ & Filamentous, sporulating & Cheng et al., 2015 \\
\hline Staphylococcus epidermidis RP62A & $\begin{array}{l}\text { Reference strain isolated from intra-vascular } \\
\text { catheter associated sepsis }\end{array}$ & +++ & ATCC collection \\
\hline Staphylococcus epidermidis $\mathrm{O}-47$ & Clinical isolate from septic arthritis & ++ & Heilmann et al., 1996 \\
\hline Staphylococcus epidermidis 1457 & $\begin{array}{l}\text { Clinical isolate from a patient with infected } \\
\text { central venous catheter }\end{array}$ & +++ & Mack et al., 1992 \\
\hline Staphylococcus epidermidis ATCC 12228 & Non-infection associated strain & --- & ATCC collection \\
\hline Staphylococcus carnosus TM300 & Meat starter culture & --- & Rosenstein et al., 2009 \\
\hline Staphylococcus aureus Newman & MSSA isolate from osteomyelitis patient & + & Lipinski et al., 1967 \\
\hline Staphylococcus aureus USA300 Lac* & CA-MRSA isolate from a wrist abscess & + & McDougal et al., 2003 \\
\hline Staphylococcus aureus RF122 & Bovine mastitis isolate & - & Fitzgerald et al., 2001 \\
\hline Staphylococcus aureus Mu50 & $\begin{array}{l}\text { Human MRSA isolate from surgical wound } \\
\text { infections, vancomycin-resistant }\end{array}$ & - & Kuroda et al., 2001 \\
\hline Staphylococcus aureus COL & Human MRSA isolate & - & Dyke et al., 1966 \\
\hline Pseudomonas aeruginosa PAO1 & Clinical isolate from wound & +++ & Dr. Vinay Pawar, Braunschweig, Germany \\
\hline Pseudomonas aeruginosa PA14 & Clinical isolate from burn wound & +++ & Dr. Vinay Pawar, Braunschweig, Germany \\
\hline
\end{tabular}

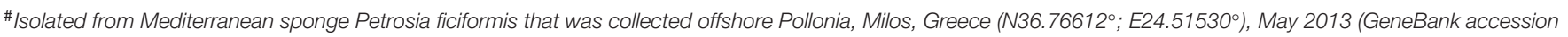

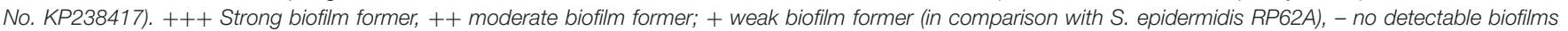
under conditions tested, -- - biofilm negative phenotype. Biofilm formation was assessed in TSB medium employing the standard crystal violet biofilm formation assay.

tubes (length $1 \mathrm{~cm}$ and $0.2 \mathrm{~cm}$ diameter; Biotronik, Berlin, Germany). Briefly, $1 \mathrm{ml}$ of $S$. epidermidis RP62A $\left(\mathrm{OD}_{600}\right.$ of 0.05 ) was transferred to 24 -well plates (Greiner bio-one, $\mathrm{GmbH}$, Germany) containing the surfaces of interest with the test substances. Control wells containing the medium extract and DMSO were maintained in parallel. Sterile controls containing the surfaces with TSB alone were included to ensure absence of contamination. All the plates were incubated at $37^{\circ} \mathrm{C}$ for $24 \mathrm{~h}$ under static conditions. Samples were then subjected to washing with sterile PBS $(2 \times)$ and subjected to SEM studies.

For SEM, samples were fixed overnight with gluteraldehyde (6.25\%) and washed with Sörenson buffer $\left(100 \mathrm{mM} \mathrm{KH}_{2} \mathrm{PO}_{4}\right.$ and $\left.100 \mathrm{mM} \mathrm{Na}_{2} \mathrm{HPO}_{4}\right)$. After dehydration with a series of steps with ethanol, samples were finally coated with gold by low vacuum sputter coating, and scanned in the electron microscopy unit, University of Würzburg.

TABLE 2 | Effect of SKC3 on strains used in the study.

\begin{tabular}{lcc}
\hline Strain & MIC & BIC $_{>75}$ \\
\hline Staphylococcus epidermidis RP62A & $31.25 \mu \mathrm{g} / \mathrm{ml}$ & $3.95 \mu \mathrm{g} / \mathrm{ml}$ \\
Staphylococcus epidermidis O-47 & $31.25 \mu \mathrm{g} / \mathrm{ml}$ & $7.81 \mu \mathrm{g} / \mathrm{ml}$ \\
Staphylococcus epidermidis 1457 & $31.25 \mu \mathrm{g} / \mathrm{ml}$ & $15.62 \mu \mathrm{g} / \mathrm{ml}$ \\
Staphylococcus aureus Newman & $31.25 \mu \mathrm{g} / \mathrm{ml}$ & $7.81 \mu \mathrm{g} / \mathrm{ml}$ \\
Staphylococcus aureus USA300 Lac* & $15.62 \mu \mathrm{g} / \mathrm{ml}$ & $3.95 \mu \mathrm{g} / \mathrm{ml}$ \\
Staphylococcus aureus RF122 & $31.25 \mu \mathrm{g} / \mathrm{ml}$ & $\mathrm{ND}$ \\
Staphylococcus aureus COL & $15.62 \mu \mathrm{g} / \mathrm{ml}$ & $\mathrm{ND}$ \\
Staphylococcus aureus Mu50 & $15.62 \mu \mathrm{g} / \mathrm{ml}$ & $\mathrm{ND}$ \\
Pseudomonas aeruginosa PAO1 & - & - \\
Pseudomonas aeruginosa PA14 & - & - \\
\hline MIC, minimum inhibitory concentration; & BlC $>75, \quad>75 \%$ & biofilm inhibitory \\
concentration; -, inactive; ND, not determined. &
\end{tabular}

\section{Cytotoxicity Profiling}

\section{In Vitro on Cell Lines}

Cytotoxicity of the purified compound SKC3 was assessed on macrophage (J774.1) and mouse fibroblast (NIH/3T3) cell lines using alamar blue assay (Huber and Koella, 1993). RPMI 1640 $(1 \times)+$ Glutamax $^{\mathrm{TM}}-1$ and DMEM $(1 \times)$ Glutamax $^{\mathrm{TM}}-1$ (Life Technologies ${ }^{\mathrm{TM}}$, United States), supplemented with $10 \%$ FCS without antibiotics, were used for culturing J774.1 and NIH/3T3 cell lines, respectively. A total of $10^{5}$ cells $/ \mathrm{ml}$ were seeded on 96well plates containing SBT348 extract $(62.5-500 \mu \mathrm{g} / \mathrm{ml})$ or SKC3 (3.95-500 $\mu \mathrm{g} / \mathrm{ml})$ and the plates were incubated at $37^{\circ} \mathrm{C}$ with $5 \%$ $\mathrm{CO}_{2}$ for $24 \mathrm{~h}$. A total of $20 \mu \mathrm{l}$ of alamar blue (Thermofischer Scientific, United States) was added to each well and the plates were incubated for a further period of $24 \mathrm{~h}$ at $37^{\circ} \mathrm{C}$ with $5 \%$ $\mathrm{CO}_{2}$. Finally, the $\mathrm{OD}_{550}$ values of the plates were measured and normalized to $\mathrm{OD}_{630}$ values. Extent of cytotoxicity was measure by comparison of extract/SKC3 treated sets with the control. $\mathrm{MeOH}$ (toxic to the cells) was used as the positive control in the experiment. DMSO at a final concentration of $1 \%$ was used as the control.

\section{In Vivo on Galleria mellonella Larvae}

Galleria mellonella larvae (at their final stage) were purchased from Mouse Live Bait (Balk, Netherlands). In vivo toxicity of SBT348 extract and SKC3 was assessed in G. mellonella using the method described previously (Gibreel and Upton, 2013; Skaf et al., 2017). Healthy larvae (clear in color without the presence of any spots or pigmentation) were used in the experiment. SBT348 extract and SKC3 at their respective test concentrations were prepared in endotoxin-free PBS (Merck, Germany) (vehicle control) and were injected in the last left pro-leg of the larvae with sterile insulin pens (BD Micro-Fine ${ }^{\mathrm{TM}}+$ Demi). A total of 10 larvae were included per group. Negative controls included 
the group that underwent no injection and injection with vehicle control only, while, positive control included the group injected with pure $\mathrm{MeOH}$ (Roth, Germany). Larval groups were incubated at $37^{\circ} \mathrm{C}$ in petri dishes (devoid of light). Larval survival rates were recorded every $24 \mathrm{~h}$ up to $120 \mathrm{~h}$. Larvae that were pigmented and did not respond to touch were scored dead and vice versa. Experiments were repeated three independent times to ensure the reproducibility of results.

\section{RNA Extraction, DNase Treatment, and RNA Quality Determination}

Staphylococcus epidermidis RP62A ( $\mathrm{OD}_{600}$ of 1.0) was treated with SKC3 $(62.5 \mu \mathrm{g} / \mathrm{ml})$ and was statically incubated in a 6well plate at $37^{\circ} \mathrm{C}$ for $20 \mathrm{~min}$ and $3 \mathrm{~h}$. Treatment with DMSO (final concentration of $3.75 \% \mathrm{v} / \mathrm{v}$ on the cells) served as the appropriate control in the experiment. RNAprotect bacteria reagent (Qiagen, Germany) was added at the respective time points for protection and stabilization of RNA. Subsequently, RNA isolation was done according to the customized protocol described by Franca et al. (2012). Three independent biological replicates each from a pool of three independent wells were performed in order to reduce the variability. Isolated RNA samples were subjected to treatment with Turbo DNA-free ${ }^{\mathrm{TM}}$ kit (Invitrogen, United States) following manufacturer's instructions and acid phenol:chloroform:isoamylalcohol (125:24:1) (Ambion, United States). Finally, pure RNA samples obtained, were precipitated with ethanol and checked for DNA contamination by PCR for icaA gene (Supplementary Figure S1).

Concentration and purity of the total RNA was evaluated spectrophotometrically using NanoDrop 2000 PEQLAB GmbH (Erlangen, Germany). The ratios $\mathrm{A}_{260} / \mathrm{A}_{280}$ (mean values of all the samples was 1.97) and $\mathrm{A}_{260} / \mathrm{A}_{230}$ (mean values of all the samples was 2.59) were used as indicators of protein and phenol/polysachharide contamination. Total RNA quality was also assessed with an Agilent 2100 Bioanalyzer (Agilent, CA, United States). RNA integrity numbers of all samples were $\sim 8.0$ or more.

\section{Ribosomal RNA Depletion, Library Preparation, and Sequencing}

Extracted RNA was depleted of ribosomal RNA using the Ribo-Zero rRNA Removal Kit for bacteria (Illumina) according to the manual. Depleted RNA was fragmented for $3 \mathrm{~min}$ at $94^{\circ} \mathrm{C}$ using the NEBNext Magnesium RNA Fragmentation Module. The RNA ends were repaired with two consecutive T4 PNK incubations ( \pm ATP) and an RppH treatment. Library preparation was performed according to the NEBNext Multiplex Small RNA Library Preparation Guide for Illumina. All adapters and primers were diluted 1:4 and 15 and 16 cycles of PCR were used, respectively. No size selection was performed at the end of the protocol. A total of 12 libraries were pooled and sequenced on a NextSeq 500 with a read length of $75 \mathrm{nt}$.

\section{Analysis of Deep-Sequencing Data}

The quality of raw reads (Phred scores, amount of duplicates and adapter) were assessed using FastQC (version-0.11.31)
(Andrews, 2010). In order to assure a high sequence quality, the Illumina reads in FASTQ format were trimmed with a cut-off phred score of 20 by cutadapt (version-1.15) (Martin, 2011) that also was used to remove the adapter sequences. The following steps were performed using the subcommand "create," "align," and "coverage" of the tool READemption (Forstner et al., 2014) (version 0.4.3) with default parameters. Reads with a length below $15 \mathrm{nt}$ where removed and the remaining reads were mapped to the reference genome sequences (NCBI accession no. NC_002976.3 (31 January 2014)) using segemehl (Hoffmann et al., 2009). Coverage plots in wiggle format representing the number of aligned reads per nucleotide were generated based on the aligned reads and visualized in the Integrated Genome Browser (Freese et al., 2016). Each graph was normalized to the total number of reads that could be aligned from the respective library. To restore the original data range and prevent rounding of small error to zero by genome browsers, each graph was then multiplied by the minimum number of mapped reads calculated over all libraries. The differentially expressed genes were identified using DESeq2 version 1.16.1 (Love et al., 2014). In all cases, only genes with maximum Benjamini-Hochberg corrected $p$-value $\left(p_{\text {adj }}\right)$ of 0.05 were classified as significantly differentially expressed. The data were represented as MA plots using R.

Differentially expressed genes (cutoff of $p$ adjusted $\leq 0.05$ and $\log _{2} \mathrm{FC} \geq 2$ or $\leq-2$ ) was used to perform Gene enrichment using the R package clusterProfiler version v3.4.4 (Yu et al., 2012). Using enrich KEGG function enrichment in KEGG pathways was analyzed. Only the pathways with Benjamini-Hochberg FDR threshold $\leq 0.05$ defined as significantly enrichment terms.

The RNA-Seq data presented in this work has been deposited at the NCBI Gene Expression Omnibus (Edgar et al., 2002) and can be accessed through GEO series accession number ${ }^{1}$ GSE109983. Samples treated with SKC3 has been referred to as C3 in the submitted files.

\section{Statistical Analysis}

All the experiments were performed three independent times with technical replicates. Data are expressed as mean \pm SEM. For all the comparisons, Student's $t$-test was used. For comparing different Kaplan-Meier survival curves from in vivo G. mellonella experiments, log-rank (Mantel-Cox) and GehanBreslow-Wilcoxon test was used. $p$-value $<0.05$ was considered as statistically significant. GraphPad Prism ${ }^{\circledR}$ version 6.01 was used for statistical analysis of experimental data.

\section{RESULTS}

\section{Anti-biofilm Potential of Streptomyces} sp. SBT348

The anti-biofilm potential of Streptomyces sp. SBT348 was identified with a preliminary anti-biofilm screening of different actinomycetes organic extracts against the strong biofilm forming S. epidermidis RP62A. Streptomyces sp. SBT348 was characterized

\footnotetext{
${ }^{1}$ https://www.ncbi.nlm.nih.gov/geo/query/acc.cgi?acc=GSE109983
} 
by its wrinkled, rough, dry, and light-yellow mycelia on ISP2 agar medium $(t=10 \mathrm{~d})$. SEM analysis revealed the filamentous nature of Streptomyces sp. SBT348. Branched networks with the presence of extracellular polymeric substance-like materials were identified in the scanning electron micrograph (Figure 1A). The ethyl acetate SBT348 extract significantly reduced the biofilm formation (at $24 \mathrm{~h}$ ) in S. epidermidis RP62A ( $p<0.0001)$. Extract at a concentration of $62.5 \mu \mathrm{g} / \mathrm{ml}$ reduced the biofilm formation by $\sim 90 \%$ and this was designated as the $\mathrm{BIC}_{90}$ ( $90 \%$ biofilm inhibition concentration). Notably, there were no significant differences in the effect beyond this concentration (Figure 1B). SBT348 extract at $\mathrm{BIC}_{90}$ or $2 \times \mathrm{BIC}_{90}$ did not further alter the growth pattern of $S$. epidermidis RP62A (compared to extract from ISP2 medium control) (Figure 1C). SBT348 extract had no antagonistic effects on pre-formed Staphylococcus epidermidis RP62A biofilms at any of the tested concentrations (15.62-500 $\mu \mathrm{g} / \mathrm{ml}$; data not shown). Cytotoxicity profiling of the extract in vitro on NIH/3T3 and J774.1 cell lines (Table 3) and in vivo on $G$. mellonella larvae demonstrated the non-toxic nature of the extract (Figure 1D). Further, no changes in the activity of the extract was observed after heat and enzymatic (proteinase $\mathrm{K}$ and trypsin) treatments (data not shown). This highlighted the presence of heat-stable and non-proteinaceous active proportion(s) in the extract.

\section{Bioassay-Guided Fractionation and Characterization of the Active Compound}

The bioassay-guided fractionation approach followed to identify the active component SKC3 (MIC of $31.25 \mu \mathrm{g} / \mathrm{ml}$ and $\mathrm{BIC}_{90}$ of $3.95 \mu \mathrm{g} / \mathrm{ml}$ ) in the extract that is shown in Figure 2A. SKC3 was further investigated in detail in the study. The pure compound SKC3 (Supplementary Figure S2) was obtained as yellow crystalline solid and was soluble in polar solvents like water, DMSO, and MeOH. Results obtained ESI-MS analysis revealed that SKC3 had a neutral mass of approximately 1258.3 Da (Figure 2B). This mass was also found in the SBT348 extract (data not shown). FT-IR spectra of SKC3 revealed some significant bands at 2,936, 3,326, 1,660, and $1,072 \mathrm{~cm}^{-1}$, representing the presence of $-\mathrm{C}-\mathrm{H}$ - stretches, $\mathrm{OH}$, amide carbonyl group, and an ester group (Figure 2C). Mass search with 1258.3 Da in databases like MarinLit ${ }^{\circledR}$ and Chemspider $^{\circledR}$ did not yield any relevant hits. Further, heat and

A

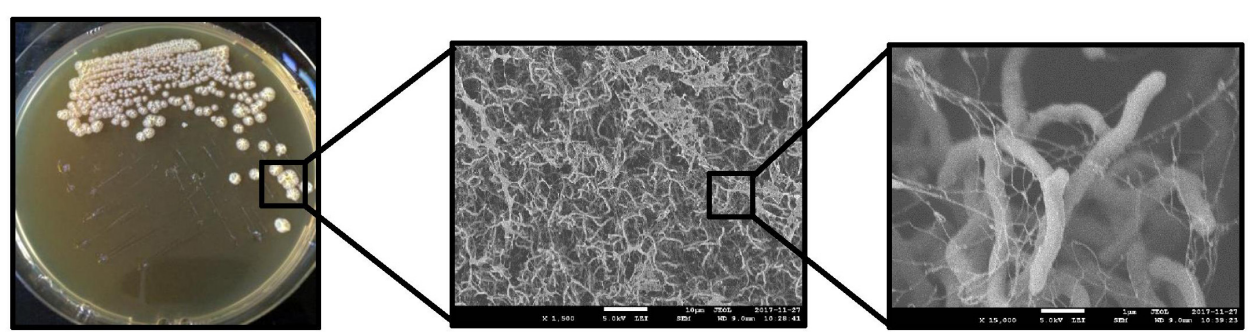

B

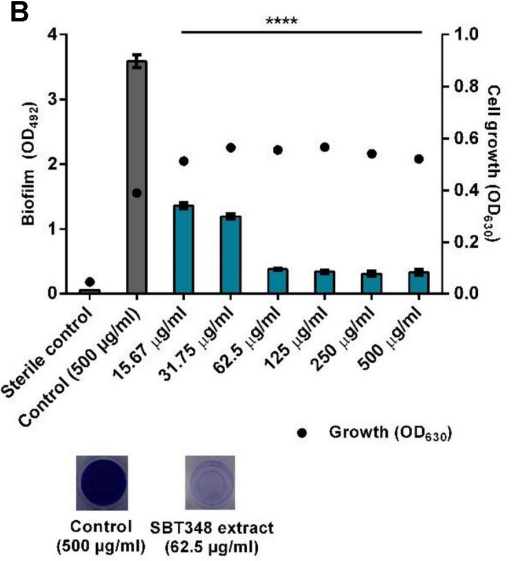

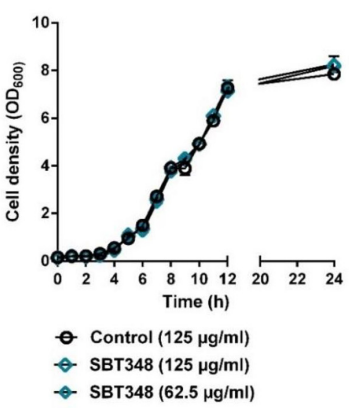

D

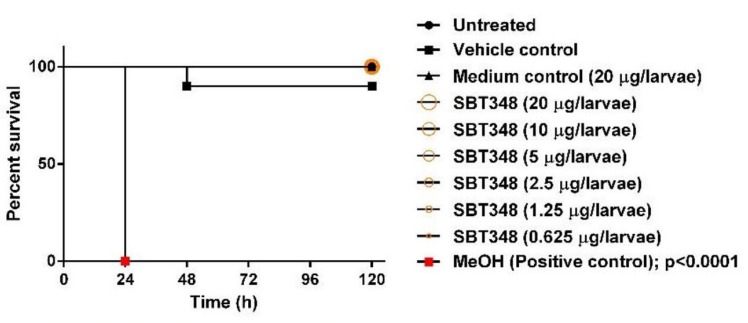

120

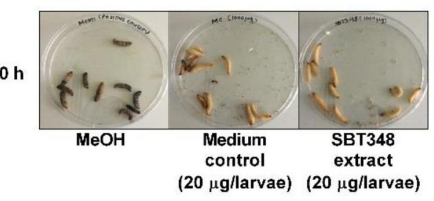

FIGURE 1 | (A) Colony morphology and scanning electron micrograph (at ×1,500 and ×15,000 magnification) of Streptomyces sp. SBT348 after $10 \mathrm{~d}$ batch fermentation on ISP2 agar plate at $30^{\circ} \mathrm{C}$. Scanning electron microscopy indicates the presence of extracellular polymeric substance-like materials in Streptomyces sp. SBT348. Scale bar: 10 and $1 \mu \mathrm{m}$. (B) Dose-dependent inhibition of biofilm formation of Staphylococcus epidermidis RP62A by ethyl acetate extract of Streptomyces sp. SBT348. (C) Influence of SBT348 extract on the growth of S. epidermidis RP62A at BIC $90(62.5 \mu \mathrm{g} / \mathrm{ml})$ and $2 \times \mathrm{BIC}_{90}(125 \mu \mathrm{g} / \mathrm{ml})$.

(D) Kaplan-Meier survival curve of Galleria mellonella larvae treated with $16 \times \mathrm{BIC}_{90}-0.5 \times \mathrm{BIC}_{90}$ of SBT348 extract $(0.625-20 \mu \mathrm{g} / \mathrm{larvae})$. Pure $\mathrm{MeOH}(20 \mu \mathrm{l})$ that was toxic to larvae was used as the positive control. Control in the experiments (B-D) consisted of ethyl acetate extract (at the respective highest concentration) from sterile ISP2 medium which was used as growth medium for Streptomyces sp. SBT348. Graphs represent the mean \pm SEM from three independent repetitions of experiment done with multiple technical replicates. ns, not significant; **** $p<0.0001$. 
TABLE 3 | In vitro cytotoxicity of SBT348 extract and SKC3 on cell lines.

\begin{tabular}{|c|c|c|c|c|}
\hline \multirow[t]{2}{*}{ Cell line } & \multicolumn{4}{|c|}{ Percentage reduction in cell viability } \\
\hline & $500 \mu \mathrm{g} / \mathrm{ml}$ & $250 \mu \mathrm{g} / \mathrm{ml}$ & $125 \mu \mathrm{g} / \mathrm{ml}$ & $3.9-125 \mu \mathrm{g} / \mathrm{ml}$ \\
\hline $\mathrm{NIH} / 3 \mathrm{T3}$ & $41.07 \pm 1.37^{* * * *}$ & NC & NC & $\mathrm{NC}$ \\
\hline J774.1 & $62.91 \pm 0.83^{* * * *}$ & $63.90 \pm 1.84^{* * * *}$ & $32.78 \pm 7.00^{* * *}$ & NC \\
\hline
\end{tabular}

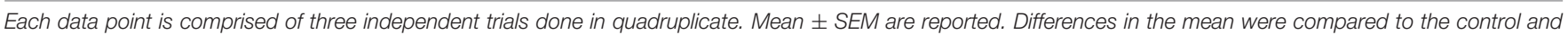

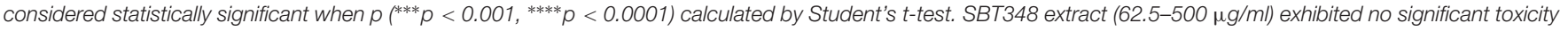
on both the cell lines tested. Positive control, MeOH reduced the cell viability of NIH/3T3 by $66.73 \pm 0.59^{* * * *}$ and J774.1 by $72.10 \pm 2.16^{* * * *}$. NC, no cytotoxicity.

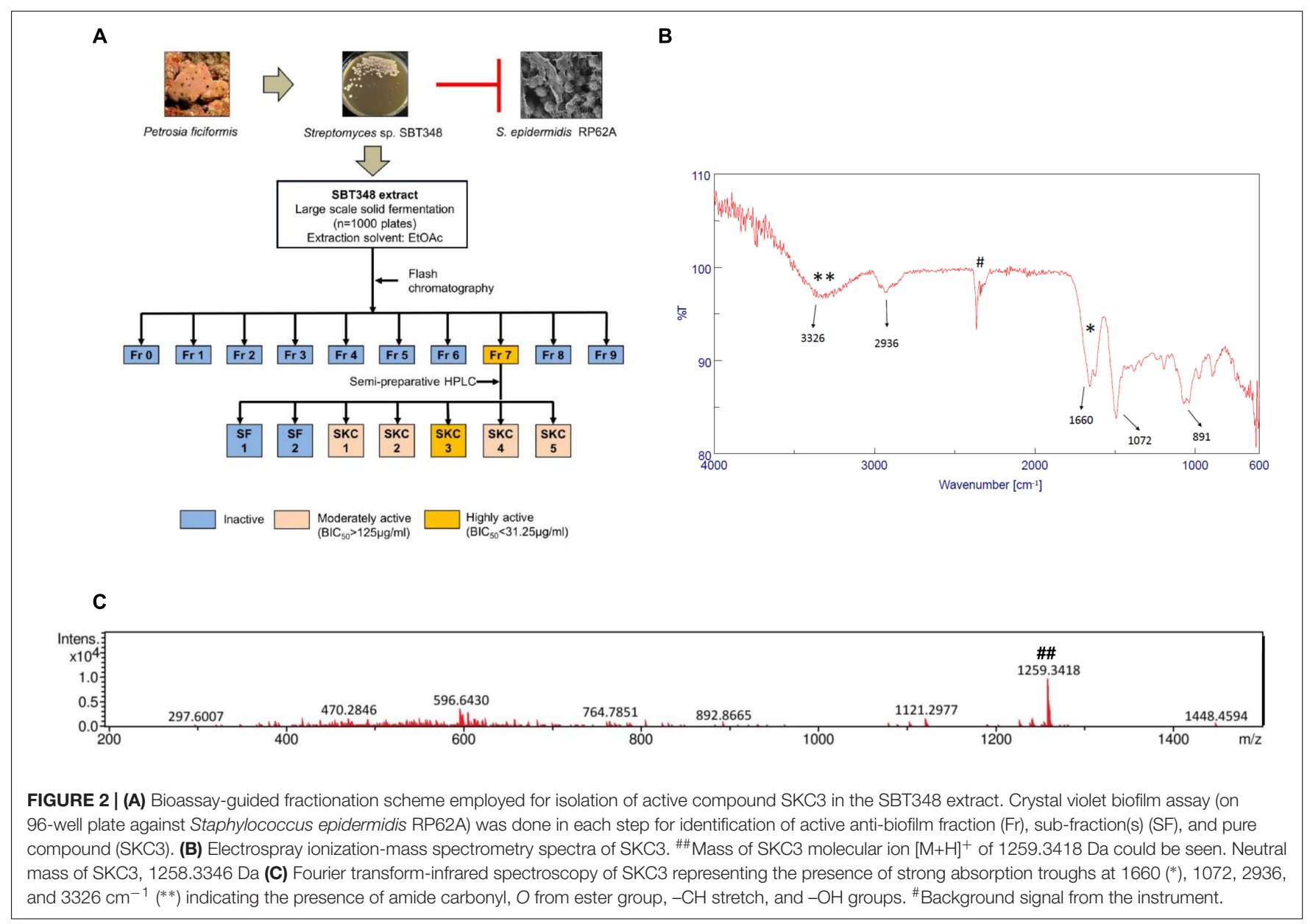

enzymatic treatments did not significantly alter the biological activity of SKC3 (Supplementary Figure S3). This was in line with the results obtained from the stability studies of the extract. The absence of relevant hits with the existing mass and spectral data indicates that SKC3 is likely to be a new compound. The structure elucidation of SKC3 is currently under investigation.

\section{Antagonistic Activities of SKC3 Against Staphylococci}

SKC3 displayed an MIC of $31.25 \mu \mathrm{g} / \mathrm{ml}$ on S. epidermidis RP62A and the sub-MIC concentrations $(1.95-<31.25 \mu \mathrm{g} / \mathrm{ml})$ effectively inhibited the biofilm formation in the crystal violet biofilm assay (Figure 3A). BIC 90 value of SKC3 was $3.95 \mu \mathrm{g} / \mathrm{ml}$. Interference of SKC3 (MIC) with the growth of S. epidermidis RP62A was further confirmed with the growth curve analysis (Figure 3B). Thus, presence of SKC3 at MIC, effectively inhibited bacterial growth (approximately 100-fold reduction in CFUs/ml; data not shown) while SKC3 at $\mathrm{BIC}_{90}$ had no significant influence. Further, SKC3 (at the highest tested concentration: $500 \mu \mathrm{g} / \mathrm{ml}$ ) had no clearing effect on existing biofilms of $S$. epidermidis RP62A (Figure 3C). Complete biofilm dispersal by $\mathrm{NaIO}_{4}(40 \mathrm{mM})$ was used a positive control in this experiment. SKC3 was also effective in inhibiting the growth and biofilm formation of other strains used in the study (Table 2). Noteworthy, SKC3 was more effective against MSSA, MRSA, and VRSA strains used in the study, but was ineffective against the tested Gram negative $P$. aeruginosa strains. 


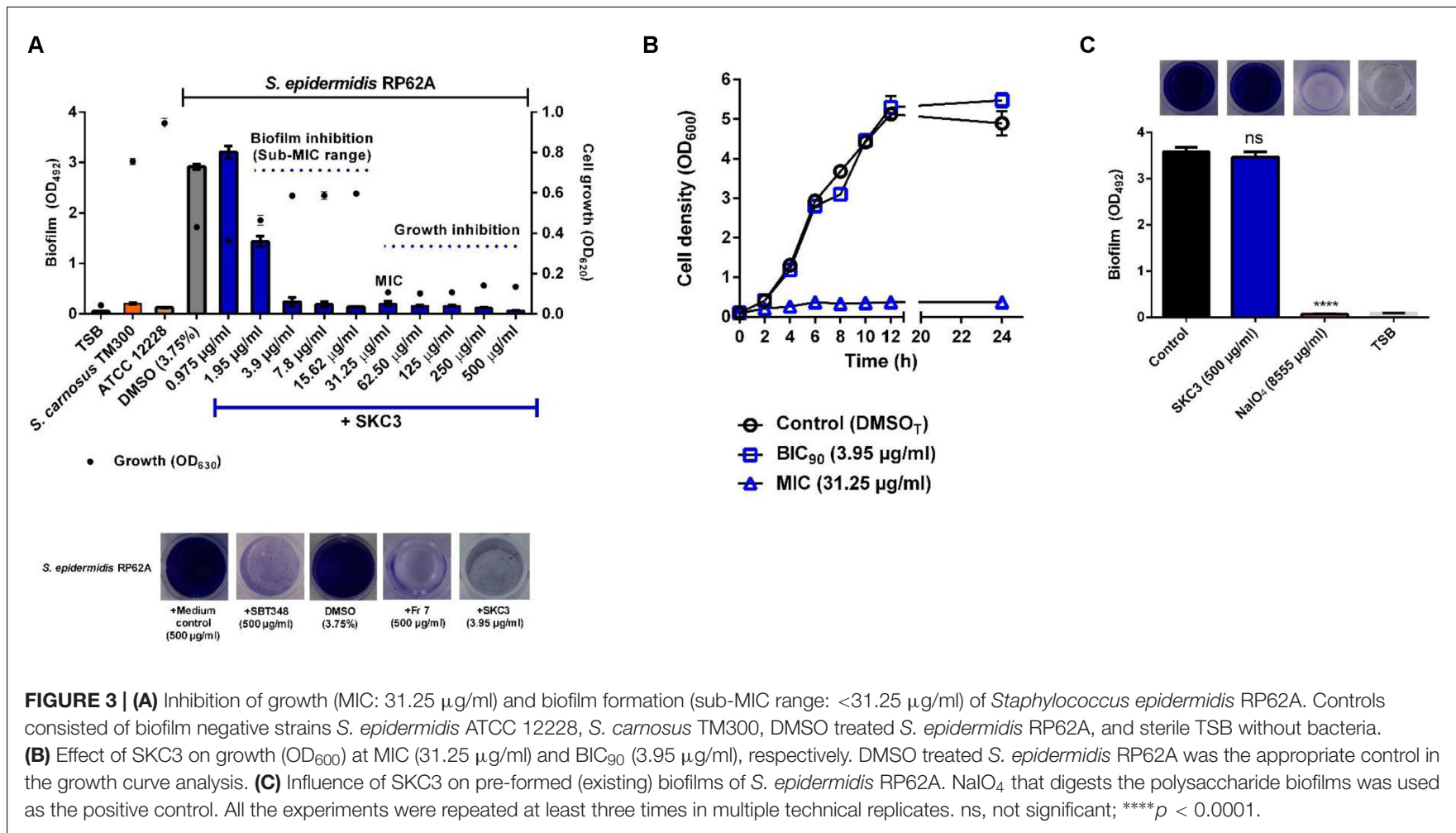

\section{SEM Analysis}

Investigation of the anti-biofilm efficacy of SKC3 at subMICs were further evaluated with SEM of S. epidermidis RP62A biofilms grown on glass, titan metal, and silicone tube surfaces. From the scanning electron micrographs, clear differences in appearance were observed in the three sterile surfaces under study. In the control sets of the surfaces (treated with DMSO; 3.75\%), three-dimensional dense biofilm structures were observed. Treatment with SKC3 $\left(\mathrm{BIC}_{90}\right.$ and $\left.2 \times \mathrm{BIC}_{90}\right)$ significantly reduced the biofilm formation on these surfaces and this further confirmed the results obtained from crystal violet biofilm assay (Figure 4). Particularly, the three-dimensional networks were absent, and the surfaces were clearly seen (between sporadic microcolonies or single cells) in the SKC3-treated sets. A closer look on the SEM images at higher magnification revealed no alterations in the cell morphology of staphylococci. These findings further point towards the anti-biofilm potential of the isolated compound SKC3.

\section{In Vitro and in Vivo Toxicity of SKC3}

In vitro toxicity assessment of SKC3 was done on mouse macrophage (J774.1) and fibroblast cell lines (NIH/3T3) using the alamar blue assay. Results from the cytotoxicity analysis demonstrated the non-toxic nature of SKC3 at effective concentrations (Table 3).

Toxicity of SKC3 was additionally assessed in vivo in the greater wax moth larvae, G. mellonella. In recent years, G. mellonella larvae have emerged as an interesting model system for evaluating the toxicity and efficacy of novel compounds and for studying various microbial infections (Gibreel and Upton, 2013; Aparecida Procopio Gomes et al., 2016; Skaf et al., 2017). The ease of handling, low maintenance costs, absence of ethical concerns, survival at human physiological temperatures are some of the advantages of using G. mellonella larvae for pre-screening of toxicity (Tsai et al., 2016). Survival rates of larvae treated with SKC3 $\left(\mathrm{BIC}_{90}-200 \times \mathrm{BIC}_{90}\right)$ are shown in Figure 5. None of the tested concentrations lead to death of the larvae, whereas, the positive control $\mathrm{MeOH}$ lead to $90 \%$ reduction in the larval survival rates. Thus, SKC3 was completely non-toxic to the larvae at the tested concentration.

\section{Transcriptome Analyses of SKC3-Treated S. epidermidis RP62A}

Total RNA sequencing was done for S. epidermidis RP62A treated with SKC3 $(62.5 \mu \mathrm{g} / \mathrm{ml})$ after $20 \mathrm{~min}$ and $3 \mathrm{~h}$ points. Global transcriptome analysis with the obtained RNA sequencing results revealed the existence of several differentially expressed genes upon SKC3 treatment. The differentially expressed genes were identified by setting the threshold of $\log _{2}$ foldchange $\geq 2$ or $\leq-2$ with an adjusted $p$-value of $<0.05$ for statistical significance. From the MA plots (Figures 6A,B), it is evident that higher number of genes were differentially expressed (upon SKC3 treatment) after $3 \mathrm{~h}$ than $20 \mathrm{~min}$. This was additionally confirmed in the PCA plot and a well-distributed grouping of the different biological replicates were observed (Supplementary Figure S4). According to the set threshold, a total of 31 genes representing $1.1 \%$ of the transcriptome were significantly altered in response to SKC3 after $20 \mathrm{~min}$ and a total of 509 genes 


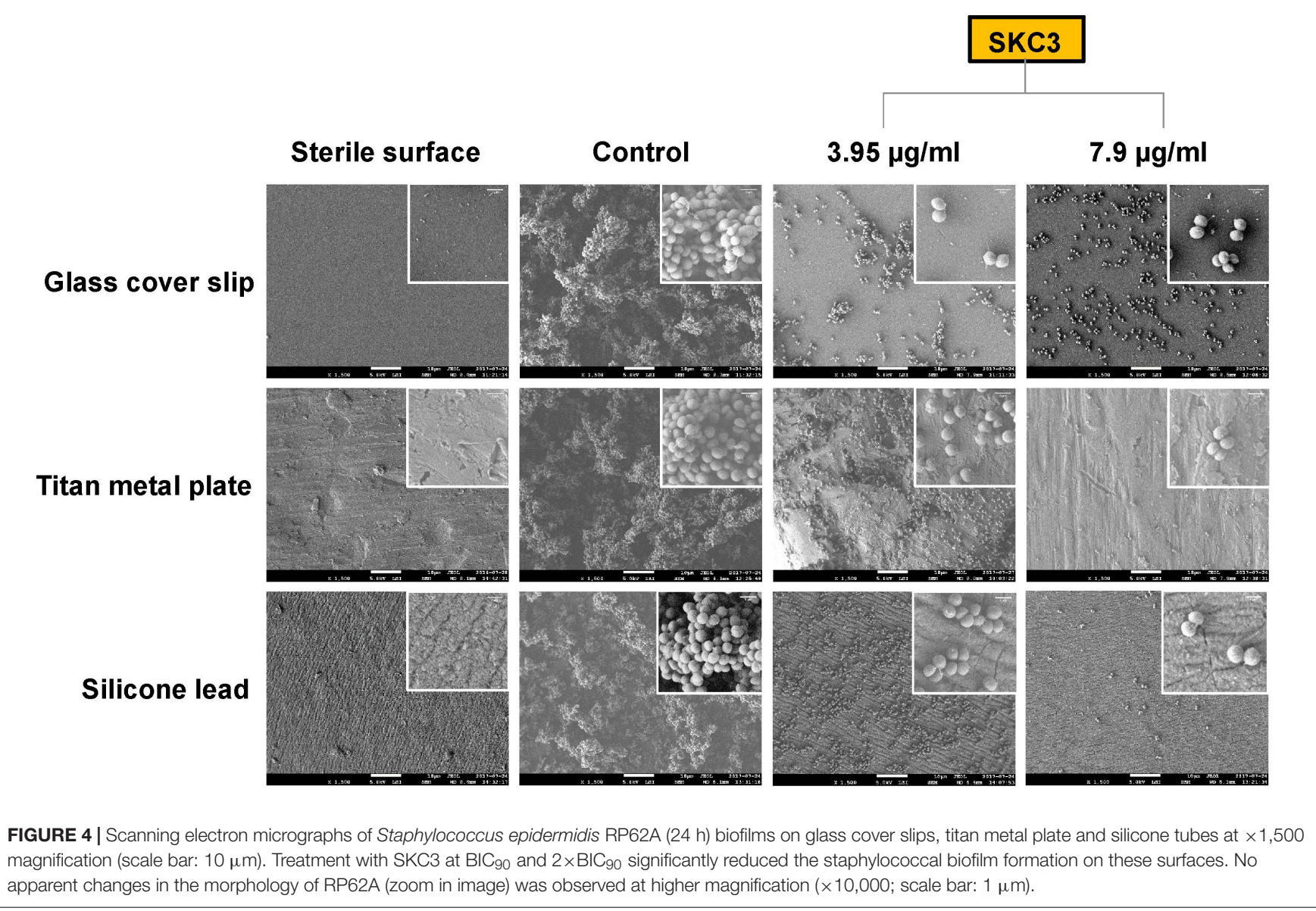

representing $19.5 \%$ of the transcriptome were significantly altered in response to SKC3 after $3 \mathrm{~h}$. Among these genes, 29 genes were upregulated, and 2 genes were downregulated after 20 min (Supplementary Table S1), whereas, 265 genes were upregulated, and 244 genes were downregulated after $3 \mathrm{~h}$ (Supplementary Table S2). After data filtering and searches in PubMed and UniProtKB, the differentially expressed genes at the two-time points were manually sorted in several categories based on their biological functions of the products they encode. Majority of the differentially regulated genes in the entire data set encoded for hypothetical proteins. Transcriptome analysis revealed that after $20 \mathrm{~min}$, several of the differentially expressed genes were attributed to signal transduction mechanism, transporters, transcription, and antibiotic response-related functions (Figure 6C). This suggests that $S$. epidermidis $\mathrm{RP} 62 \mathrm{~A}$ responds to SKC3 by signal transduction mechanisms and by expressing several transcription, transporters, and antibiotic-stress related genes. Transcriptome analysis further revealed that after $3 \mathrm{~h}$, several of the metabolic processes (pertaining to carbon, amino acid, protein, lipid, nucleotide, and energy metabolism) and transport processes were strongly affected (Figure 6D). Functional enrichment analysis also yielded similar antagonistic effects of SKC3 on metabolism (Supplementary Figure S5). A list of all differentially regulated metabolism-related genes and virulence genes upon SKC3 treatment after $3 \mathrm{~h}$ are further detailed in Table 4. Overall, the results from transcriptome analysis suggest that SKC3 possibly works by interference with the overall metabolism of staphylococci.

\section{DISCUSSION}

The increased use of implanted medical devices, the subsequent risk of biofilm formation on these devices and the emergence of drug-resistant strains has altogether imposed a heavy burden on patient and health care systems (Becker et al., 2014; WHO, 2014; Casillo et al., 2017). About, 5,027 anti-biofilm agents against Gram-positive and negative bacteria, and fungi have been reported between 1988 and 2017 (Rajput et al., 2018). However, up to our knowledge none of them have been successfully translated to the market for clinical and medical applications. Our research aimed at harnessing the potential of marine sponge-derived actinomycetes for discovery of novel antibacterial and anti-biofilm compounds (Abdelmohsen et al., 2014a,b; Dashti et al., 2014). Actinomycetes from marine sponges represent an untapped reservoir of a wide range of unforeseen biological compounds (Xi et al., 2012; Abdelmohsen et al., 2015; Sun et al., 2015). Previous results have demonstrated the anti-biofilm efficacy of an organic extract from Streptomyces 

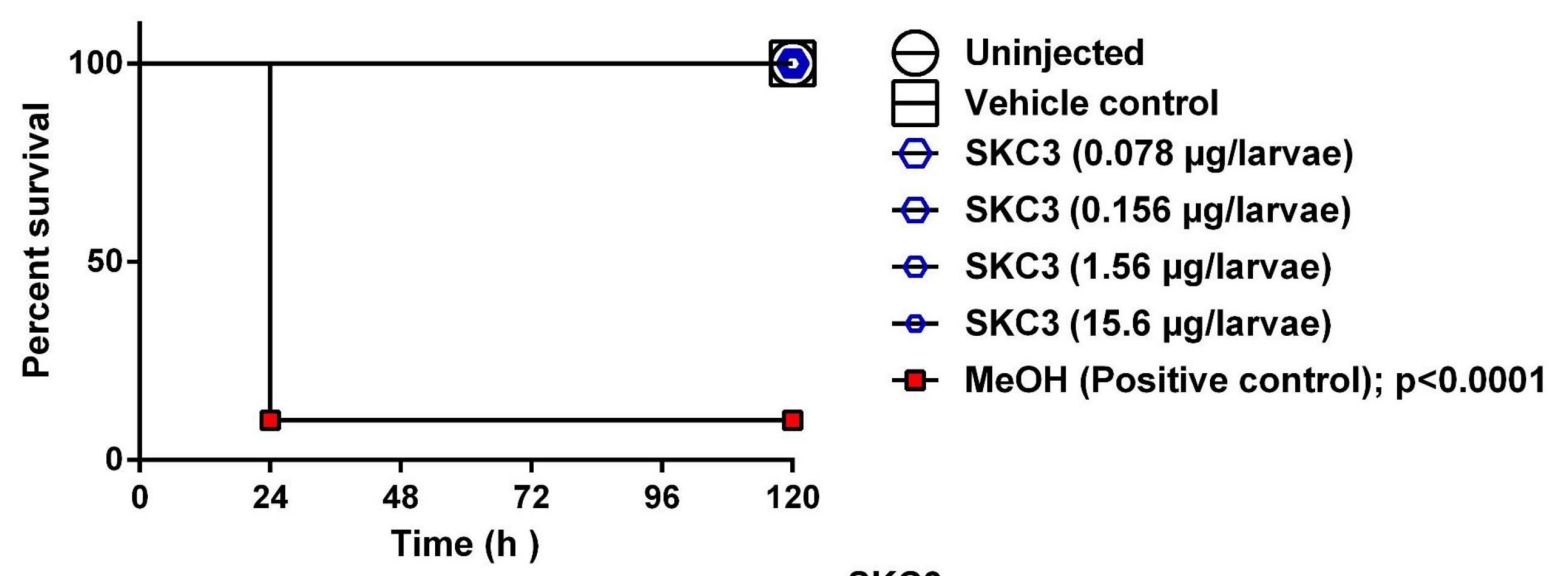

$120 \mathrm{~h}$

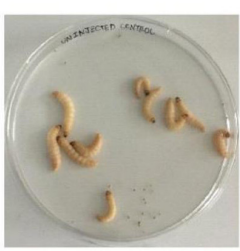

Uninjected

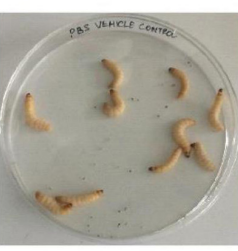

Vehicle control

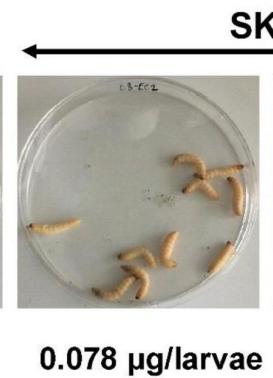

$\left(\mathrm{BIC}_{90}\right)$
SKC3

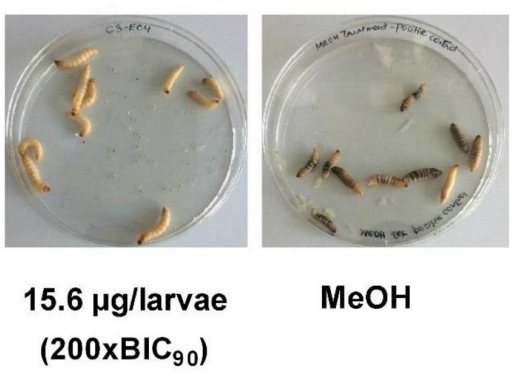

FIGURE 5 | In vivo toxicity evaluation of SKC3 on Galleria mellonella larvae. No death was observed in the larval groups treated with vehicle control (1× PBS; endotoxin-free) and SKC3 (BIC90 $\left.-200 \times \mathrm{BIC}_{90}\right)$. MeOH treatment lead to $90 \%$ death of the larvae.

sp. SBT343 isolated from marine sponge Petrosia ficiformis (Balasubramanian et al., 2017). In this study, we describe the antistaphylococcal activity of another strain Streptomyces sp. SBT348 isolated from the same sponge. We applied a bioassay-guided fractionation strategy to identify, isolate, and purify the active compound responsible for this activity.

Streptomyces sp. SBT348 is a filamentous Gram-positive bacterium that was previously shown to possess distinct metabolomic and rich chemistry profiles with strong biological activities (Cheng et al., 2015, 2017). SEM of the $10 \mathrm{~d}$ old Streptomyces sp. SBT348 culture used for extraction and isolation of the bioactive SKC3 indicated the presence of biofilm-like networks (Figure 1A). This extends the possibility of SKC3 to be a compound produced in the biofilm networks that is antagonistic to other bacteria. However, more experiments are needed to confirm the same.

Leary et al. (2017) proposed a combination of autoclave and chlorhexidine treatment for complete removal of biofilms from orthopedic materials. Alternative, coating-based strategies have been proposed to prevent this phenomenon (Windolf et al., 2014). The isolated compound SKC3 effectively inhibited the growth and biofilm formation of different staphylococcal strains (Figure 3 and Table 2). Kinetics of staphylococcal biofilm formation in the presence of SKC3 revealed its action during early steps of biofilm formation between 3 and $4 \mathrm{~h}$ (Supplementary Figure S6). Further, the inefficacy of SKC3 against dispersing pre-formed biofilms highlights its usage in prevention of staphylococcal infections. This is advantageous, since, targeting the disassembly could lead to increased inflammatory response and severity of a disease (Franca et al., 2016). SKC3 was also shown to inhibit the staphylococcal biofilm formation on different medically relevant surfaces (glass, titan metal, and silicone tubes). The non-toxic nature of SKC3 in vitro (cell lines) and in vivo ( $G$. mellonella larvae) explains its applicability as antimicrobial and anti-biofilm agents on medical devices. As a step forward, the potential of SKC3 to protect G. mellonella from $S$. aureus USA300 Lac* was also assessed in an independent experiment. Results obtained indicated that SKC3 could not protect the larvae from staphylococcal infection (data not shown). The exact reason behind this failure remains unclear. However, further investigations are needed to evaluate the toxicity and in vivo antimicrobial efficacy of SKC3 on higher in vivo model systems to support its usage. The huge mass (1258.3 Da), stability towards heat and enzymatic treatments, and the absence of relevant hits in several databases point towards a complex structure of SKC3. Thus, SKC3 is expected to be a new compound and further NMR spectrometric investigations to elucidate its complete structure are currently in progress.

Transcriptomics have been increasingly used for understanding the responses of staphylococci to antimicrobial agents and for obtaining insights into the antimicrobial mode of action (Sianglum et al., 2012; Chung et al., 2013; Qin et al., 2014; Wang et al., 2018). In our study, the global gene expression pattern of SKC3 treated S. epidermidis RP62A was studied by 


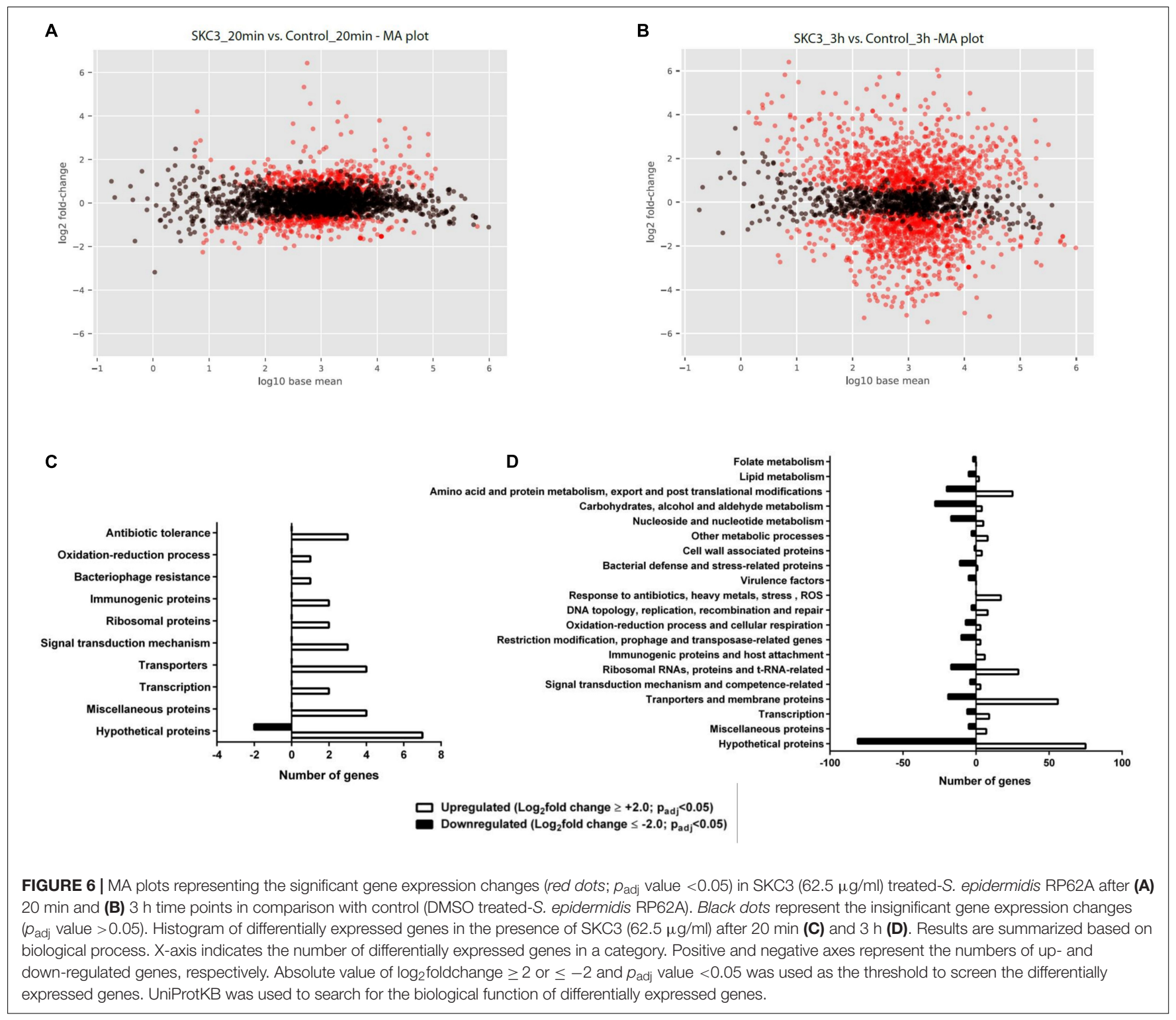

RNA sequencing and transcriptome analysis (after 20 min and $3 \mathrm{~h}$ post treatment). Functional classification of all the genes regulated by SKC3 could be seen in Figures 6C,D.

Transcriptome data from early time point $(20 \mathrm{~min})$ indicated that genes encoding a two-component system (sensor histidine kinase and response regulator), several proteins involved in transport of macromolecules, such as ATP-binding cassette (ABC) transporters and quaternary ammonium compound efflux pumps (SugE) were significantly upregulated. ABC transporters are often involved in multi-drug resistance by serving as efflux pumps for transport of anti-infectives (Lage, 2003). SugE, a drug efflux pump belonging to the small multi-drug resistance family (SMR) was shown to be involved in resistance to a narrow range of quaternary ammonium compounds in Escherichia coli (Chung and Saier, 2002). However, these ABC transporters and sugE regulated by SKC3 have not been documented to be involved in resistance to antimicrobial compounds in S. epidermidis till date.
Further studies are needed to understand the exact roles of these transporters and efflux pump in this organism. Thus, it could be presumed that after 20 min $S$. epidermidis $\mathrm{RP} 62 \mathrm{~A}$ recognizes SKC3 by a yet unknown two-component system and reacts by expressing a variety of transporters.

Transcriptome data from the late time point $(3 \mathrm{~h})$ indicated that genes encoding for hypothetical proteins were the most differentially regulated (representing 30.64\% of the total differentially expressed genes after $3 \mathrm{~h}$ ). Major fraction of the known differentially expressed genes after $3 \mathrm{~h}$ included the genes encoding proteins involved in global metabolism (representing $23.37 \%$ of the total differentially expressed genes), and transporters and membrane proteins (representing $14.73 \%$ of the total differentially expressed genes). In addition, bacterial stress and defense related proteins were strongly downregulated indicating the sensitivity of bacterial cells at this time point. Like the $20 \mathrm{~min}$ transcriptome data, several $\mathrm{ABC}$ 
TABLE 4 | List of metabolism-related genes affected in response to SKC3 after $3 \mathrm{~h}$.

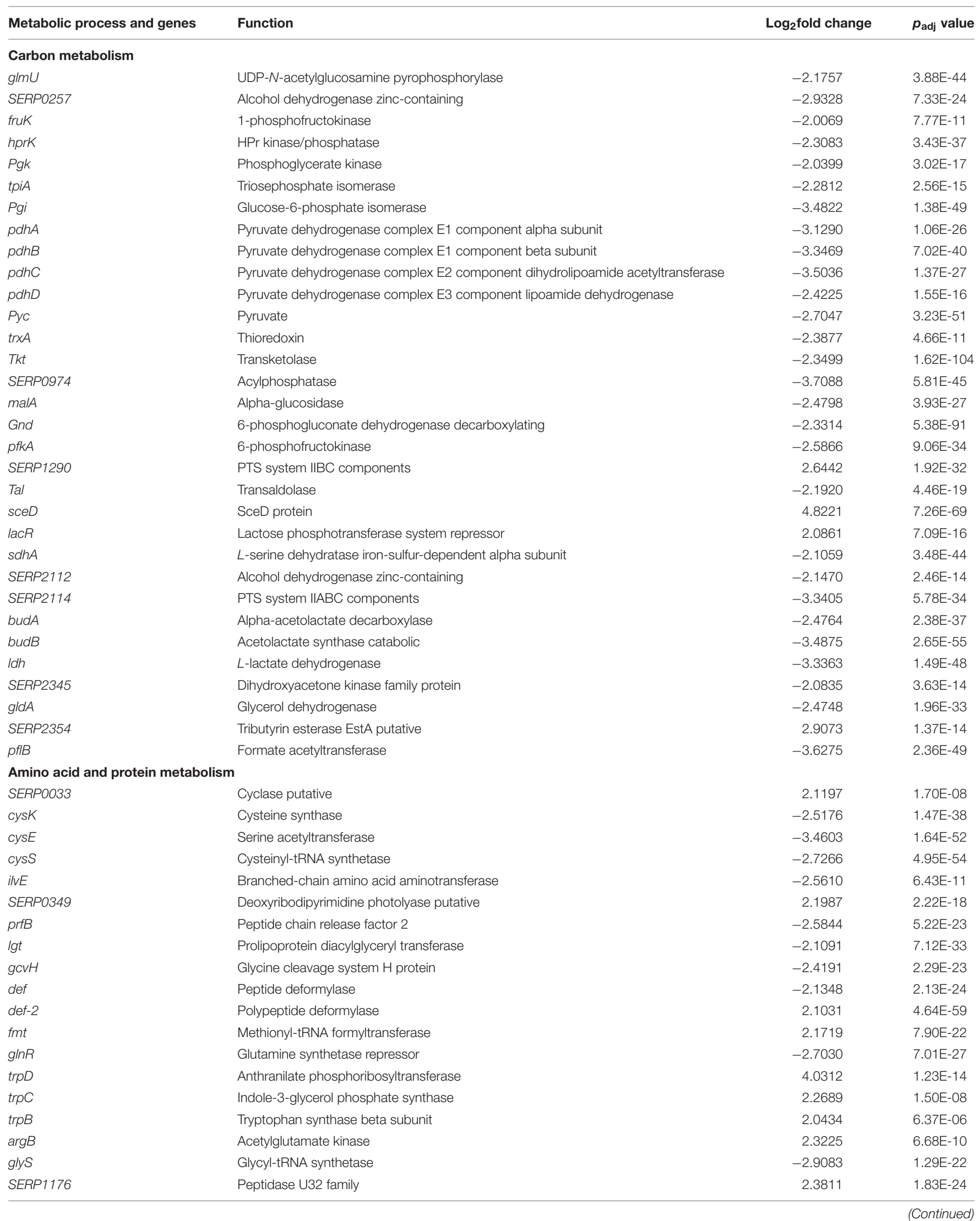


TABLE 4 | Continued

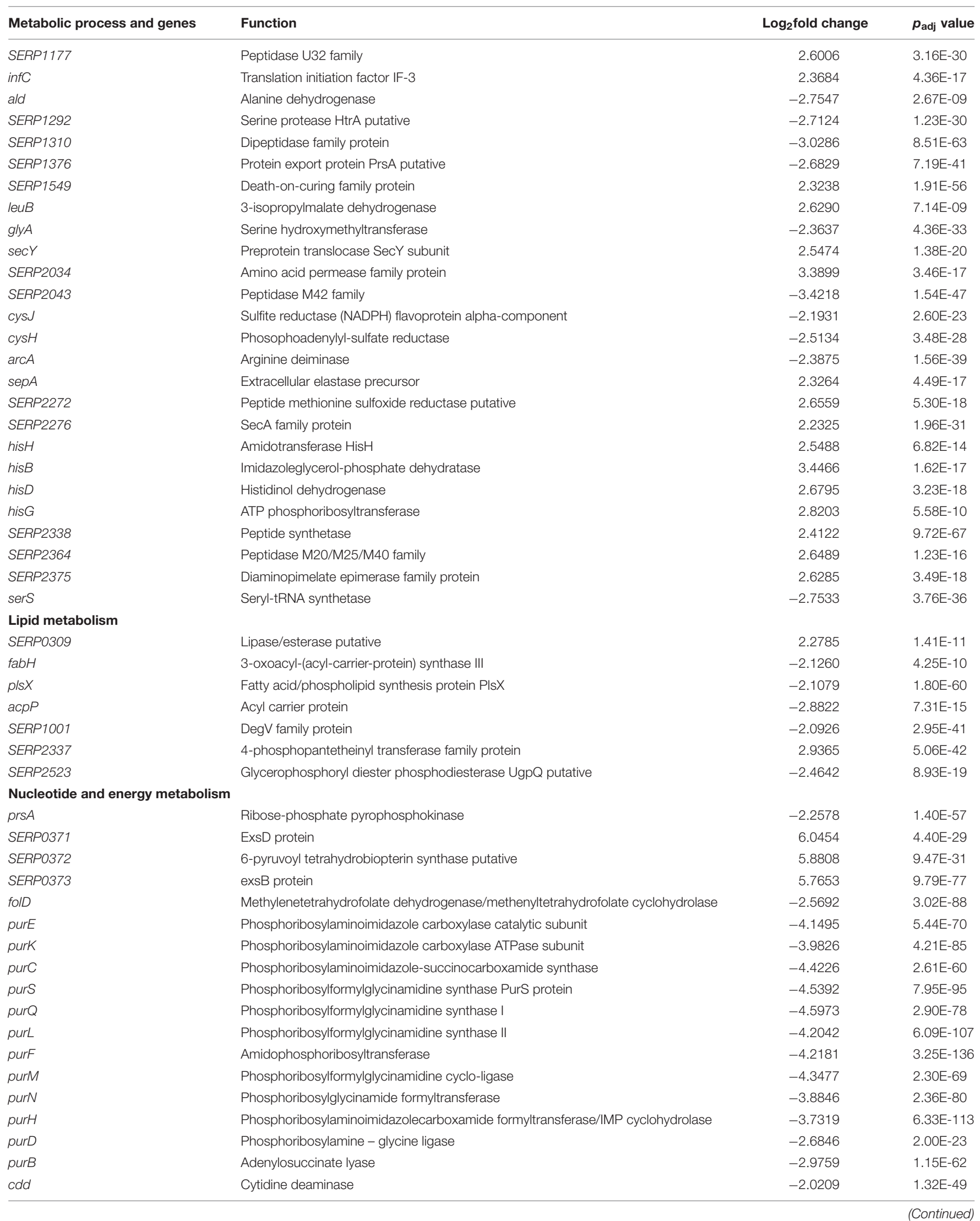


TABLE 4 | Continued

\begin{tabular}{|c|c|c|c|}
\hline Metabolic process and genes & Function & $\log _{2}$ fold change & $p_{\text {adj }}$ value \\
\hline thil & Thiamine biosynthesis protein Thil & 2.6751 & $1.97 \mathrm{E}-48$ \\
\hline Fhs & Formate - tetrahydrofolate ligase & -3.4566 & $2.24 \mathrm{E}-39$ \\
\hline upp & Uracil phosphoribosyltransferase & -2.2580 & $1.20 \mathrm{E}-35$ \\
\hline adk & Adenylate kinase & 2.5524 & $1.03 E-10$ \\
\hline SERP1865 & Inosine-uridine preferring nucleoside hydrolase family protein & -2.0061 & 2.04E-09 \\
\hline rbsk & Ribokinase & -2.2333 & $3.77 \mathrm{E}-29$ \\
\hline \multicolumn{4}{|l|}{ Other Metabolic processes } \\
\hline SERP0250 & Acetyltransferase GNAT family & -2.4617 & 3.97E-40 \\
\hline SERP0461 & Glyoxalase family protein & 2.8462 & $1.43 \mathrm{E}-08$ \\
\hline SERP0556 & Fumarylacetoacetate hydrolase family protein & -2.1019 & 4.39E-07 \\
\hline SERP0561 & Hydrolase haloacid dehalogenase-like family & -2.2982 & $1.85 E-41$ \\
\hline SERP1178 & O-methyltransferase family protein & 2.3694 & $4.74 \mathrm{E}-47$ \\
\hline SERP1280 & Aminotransferase class $\mathrm{V}$ & 2.7479 & $3.78 \mathrm{E}-43$ \\
\hline SERP1918 & Amidohydrolase family protein & 2.1722 & $5.93 E-10$ \\
\hline SERP1996 & Acetyltransferase GNAT family & 2.0172 & $4.71 \mathrm{E}-05$ \\
\hline SERP2054 & Glycosyl transferase group 1 family protein & 2.5257 & 1.06E-23 \\
\hline SERP2299 & $N$-acetyltransferase family protein & 2.6212 & $2.47 \mathrm{E}-16$ \\
\hline SERP2547 & YjeF-related protein & 3.2688 & 4.13E-16 \\
\hline
\end{tabular}

Only genes with a $\log _{2}$ fold change $\geq 2$ or $\leq-2$ and a $p_{\text {adj }}$ value $<0.05$ were included.

transporters, ion transporters, drug transporters, and efflux pump were influenced in the presence of SKC3 after $3 \mathrm{~h}$. These are speculated to be the typical responses of $S$. epidermidis to toxic agents (Putman et al., 2000; Cecil et al., 2011). However, the specific effects of SKC3 on metabolism are much stronger. Interference with metabolism involved differential regulation of genes involved in carbon metabolism (down regulation of genes related to processes of glycolysis, gluconeogenesis, pentose phosphate pathway, glycerol, fructose, and lactose metabolism), lipid metabolism (repression of genes related to fatty acid biosynthesis and phospholipid metabolism), nucleotide and energy metabolism (repression of several genes related to purine biosynthetic process from de novo and salvage pathways), and amino acid, and protein metabolism (repression in biosynthesis of cysteine, isoleucine, leucine, valine, glycine, glutamine, and lipoproteins; repression of alanine and arginine catabolism; up regulation in biosynthesis of tryptophan, arginine, and histidine).

Particularly, the purEKCSQLFMNHD operon, purA, purB, and purR genes responsible for de novo purine biosynthesis were the heavily downregulated genes in SKC3-treated S. epidermidis RP62A (Supplementary Figure S7). Purine biosynthesis is vital for various cellular processes and bacterial growth. The purine biosynthetic process involves conversion of $5^{\prime}$-phosporibosyl$\alpha$-pyrophosphate (PRPP) to inositol monophosphate (IMP). IMP is then converted to adenosine monophosphate (AMP) and guanosine monophosphate (GMP) in independent steps. Purine biosynthesis is costly to the cell involving the consumption of ATPs in multiple steps. The repression of purine biosynthesis by SKC3 could lead to reduced energy production, amino acid biosynthesis, and DNA synthesis in staphylococci. Thus, the staphylococcal cells could get metabolically stressed in the presence of SKC3. Further, defects in purine biosynthesis are known to negatively affect the biofilm formation. Mutations in purine biosynthetic genes of Photorhabdus temperata ( $p u r L$ ), Streptococcus sanguinis (purB and purL), Burkholderia sp. (purL, purM, and purT), and Pseudomonas fluorescens Pf0-1 (purD, purH, purL, purC, purM, purF, purK, and purE) led to a defect in the biofilm formation of these bacteria (Ge et al., 2008; Ruisheng and Grewal, 2011; Kim et al., 2014a,b; Yoshioka and Newell, 2016). purR in staphylococci was also previously reported to indirectly regulate biofilm formation through an indirect mechanism (Mack et al., 2007). In a recent study, mutants of purEKCSQLFMNHD operon, purA, purB, and purR genes obtained by genome-wide screening of transposon library in $S$. aureus USA300 were shown to possess altered microcolony (biofilm) formation and growth on an agar plate model (Wermser and Lopez, 2018). Interestingly, there was no direct remarkable influence of SKC3 on the transcription of ica locus $(3 \mathrm{~h})$ encoding the polysaccharide intercellular adhesin (PIA) responsible for biofilm formation in S. epidermidis. Instead, virulence factors like the phenol soluble modulins $\alpha$ and $\beta$ (proinflammatory cytolysins) involved in biofilm structuring and detachment processes (Otto, 2009; Fey and Olson, 2010) and hemolysin (putative) were down-regulated. From these findings, it could be perceived that SKC3 could possibly repress the staphylococcal biofilm formation via downregulation of purine biosynthetic genes. However, further research on the regulatory linkage between purine metabolism and biofilm formation is needed.

Overall, it is evident from the data that SKC3 has multiple metabolic targets including several unexploited pathways. The antagonistic effect of SKC3 on staphylococcal metabolism is in line with the findings from previously reported antibiotic compounds. Various natural products and anti-staphylococcal compounds like betulinaldehyde, benzimidazole 
derivatives, bisquaternary bisnapthalimide, isoquinolines, lupeol, rhodomyrtone, and stigmasterol were previously shown to interfere with staphylococcal metabolism (involving interference with processes like carbon metabolism, DNA metabolism and replication, fatty acid biosynthesis, purine metabolism, synthesis of ribosomal proteins, transport of compounds, etc.) (Cecil et al., 2011, 2015; Menzel et al., 2011; Sianglum et al., 2012; Chung et al., 2013; Adnan et al., 2017; Kong et al., 2018).

In conclusion, the anti-biofilm compound SKC3 was isolated from the chemically diverse strain Streptomyces sp. SBT348 with the aid of bioassay guided-fractionation. SKC3 exhibited antagonistic effects against growth and biofilm formation (at concentrations less than MICs) of several staphylococcal strains tested without exhibiting apparent in vitro and in vivo toxicity. Transcriptome analysis revealed the interference of SKC3 with several metabolic processes (carbon, protein, lipid, nucleotide, and energy metabolism) of staphylococci. However, further experimental data is needed to elucidate the exact antistaphylococcal mode of action of SKC3.

\section{AUTHOR CONTRIBUTIONS}

TO, UA, UHO, UHU, KF, and WZ conceived and designed the experiments. SB, JS, and RB performed the experiments. SB, JS, $\mathrm{RB}$, and TO analyzed the data. SB, JS, RB, UHO, KF, UHU, WZ, UA, and TO prepared the manuscript. SB, TO, UA, UHO, $\mathrm{UHU}, \mathrm{KF}$, and WZ revised the manuscript. All authors read and approved the final manuscript.

\section{FUNDING}

This work was supported by the SeaBioTech project that is funded by the European Commission within its FP7 Program, under the thematic area KBBE.2012.3.2-01 (Grant Number: 311932). Financial support to TO and UHU was provided by the Deutsche Forschungsgemeinschaft (SFB 630 TP A5 and Z1) and by the European Commission within its FP7 Program to UHU, under the thematic area KBBE.2012.3.2-01 with Grant Number

\section{REFERENCES}

Abdelmohsen, U. R., Balasubramanian, S., Oelschlaeger, T. A., Grkovic, T., Pham, N. B., Quinn, R. J., et al. (2017). Potential of marine natural products against drug-resistant fungal, viral, and parasitic infections. Lancet Infect. Dis. 17, e30-e41. doi: 10.1016/S1473-3099(16)30 323-1

Abdelmohsen, U. R., Bayer, K., and Hentschel, U. (2014a). Diversity, abundance and natural products of marine sponge-associated actinomycetes. Nat. Prod. Rep. 31, 381-399. doi: 10.1039/c3np70111e

Abdelmohsen, U. R., Grkovic, T., Balasubramanian, S., Kamel, M. S., Quinn, R. J., and Hentschel, U. (2015). Elicitation of secondary metabolism in actinomycetes. Biotechnol. Adv. 33, 798-811. doi: 10.1016/j.biotechadv.2015.06.003

Abdelmohsen, U. R., Yang, C., Horn, H., Hajjar, D., Ravasi, T., and Hentschel, U. (2014b). Actinomycetes from Red Sea sponges: sources for chemical and phylogenetic diversity. Mar. Drugs 12, 2771-2789. doi: 10.3390/md1205 2771
311932 (SeaBioTech). JS was funded by the German Academic Exchange Service (DAAD) (Grant Number: 57169181). SB was supported by a fellowship of the German Excellence Initiative to the Graduate School of Life Sciences, University of Würzburg. Work of WZ is supported by DFG through SFB-TR34 (INST 292/67; B04) and SPP1617 (ZI 665/2).

\section{ACKNOWLEDGMENTS}

We thank Dr. Cheng Cheng for providing the actinomycete strains and technical assistance, Hilde Merkert and Daniela Bunsen for assisting the confocal and electron microscopy studies, Antonio Ferraro, Juliane Adelmann, and Dr. Matthias Grüne (all University of Würzburg) for the LC and MS measurements. We acknowledge Dr. Vinay Pawar (Helmholtz Centre for Infection Research, Braunschweig, Germany) for providing the biofilm forming Pseudomonas aeruginosa strains PAO1 and PA14 for the study. We are grateful to Dr. rer. nat. Andrea Ewald (Lehrstuhl für Funktionswerkstoff, ZMK Klinik, Würzburg, Germany) and Dr. med. Jörn Strasen (ZEMM, Universitätsklinikum Würzburg) for providing the titan metal plate and silicone electrodes for biofilm experiments. We also thank Dr. Knut Ohlsen (Institute for Molecular Infection Biology, University of Würzburg) for providing the drugresistant $S$. aureus strains and providing his expertise in the study. We hereby confirm that the isolate Streptomyces sp. SBT348 was collected during our EUH2020 Project "SeaBioTech." We further confirm that these collection efforts comply with the "The Nagoya Protocol on Access to Genetic Resources and the Fair and Equitable Sharing of Benefits Arising From their Utilization to the Convention on Biological Diversity".

\section{SUPPLEMENTARY MATERIAL}

The Supplementary Material for this article can be found online at: https://www.frontiersin.org/articles/10.3389/fmicb. 2018.01473/full\#supplementary-material

Adnan, S., Ibrahim, N., and Yaacob, W. A. (2017). Transcriptome analysis of methicillin-resistant Staphylococcus aureus in response to stigmasterol and lupeol. J. Glob. Antimicrob. Resist. 8, 48-54. doi: 10.1016/j.jgar.2016.10.006

Andrews, S. (2010). FastQC: A Quality Control Tool for High Throughput Sequence Data. Available at: http://www.bioinformatics.babraham.ac.uk?/projects/ fastqc/ [accessed October 6, 2011].

Aparecida Procopio Gomes, L., Alves Figueiredo, L. M., Luiza Do Rosario Palma, A., Correa Geraldo, B. M., Isler Castro, K. C., Ruano de Oliveira Fugisaki, L., et al. (2016). Punica granatum L. (Pomegranate) extract: in vivo study of antimicrobial activity against Porphyromonas gingivalis in Galleria mellonella model. Sci. World J. 2016:8626987.

Balasubramanian, S., Othman, E. M., Kampik, D., Stopper, H., Hentschel, U., Ziebuhr, W., et al. (2017). Marine sponge-derived Streptomyces sp. SBT343 extract inhibits staphylococcal biofilm formation. Front. Microbiol. 8:236. doi: 10.3389/fmicb.2017.00236

Barros, M., Branquinho, R., Grosso, F., Peixe, L., and Novais, C. (2014). Linezolidresistant Staphylococcus epidermidis, Portugal, 2012. Emerg. Infect. Dis. 20, 903-905. doi: 10.3201/eid2005.130783 
Beau, J., Mahid, N., Burda, W. N., Harrington, L., Shaw, L. N., Mutka, T., et al. (2012). Epigenetic tailoring for the production of anti-infective cytosporones from the marine fungus Leucostoma persoonii. Mar. Drugs 10, 762-774. doi: 10.3390/md10040762

Becker, K., Heilmann, C., and Peters, G. (2014). Coagulase-negative staphylococci. Clin. Microbiol. Rev. 27, 870-926. doi: 10.1128/CMR.00109-13

Bjarnsholt, T., Ciofu, O., Molin, S., Givskov, M., and Hoiby, N. (2013). Applying insights from biofilm biology to drug development - can a new approach be developed? Nat. Rev. Drug Discov. 12, 791-808. doi: 10.1038/nrd4000

Casillo, A., Papa, R., Ricciardelli, A., Sannino, F., Ziaco, M., Tilotta, M., et al. (2017). Anti-biofilm activity of a long-chain fatty aldehyde from antarctic Pseudoalteromonas haloplanktis TAC125 against Staphylococcus epidermidis biofilm. Front. Cell. Infect. Microbiol. 7:46. doi: 10.3389/fcimb.2017.00046

Cecil, A., Ohlsen, K., Menzel, T., Francois, P., Schrenzel, J., Fischer, A., et al. (2015). Modelling antibiotic and cytotoxic isoquinoline effects in Staphylococcus aureus, Staphylococcus epidermidis and mammalian cells. Int. J. Med. Microbiol. 305, 96-109. doi: 10.1016/j.ijmm.2014.11.006

Cecil, A., Rikanovic, C., Ohlsen, K., Liang, C., Bernhardt, J., Oelschlaeger, T. A., et al. (2011). Modeling antibiotic and cytotoxic effects of the dimeric isoquinoline IQ-143 on metabolism and its regulation in Staphylococcus aureus, Staphylococcus epidermidis and human cells. Genome Biol. 12:R24. doi: 10.1186/ gb-2011-12-3-r24

Cheng, C., Macintyre, L., Abdelmohsen, U. R., Horn, H., Polymenakou, P. N., Edrada-Ebel, R., et al. (2015). Biodiversity, anti-trypanosomal activity screening, and metabolomic profiling of actinomycetes isolated from mediterranean sponges. PLoS One 10:e0138528. doi: 10.1371/journal.pone. 0138528

Cheng, C., Othman, E. M., Stopper, H., Edrada-Ebel, R., Hentschel, U., and Abdelmohsen, U. R. (2017). Isolation of petrocidin A, a new cytotoxic cyclic dipeptide from the marine sponge-derived bacterium Streptomyces sp. SBT348. Mar. Drugs 15:E383. doi: 10.3390/md15120383

Chung, P. Y., Chung, L. Y., and Navaratnam, P. (2013). Identification by gene expression profiling analysis, of novel targets in Staphylococcus aureus treated with betulinaldehyde. Res. Microbiol. 164, 319-326. doi: 10.1016/j.resmic.2013. 01.005

Chung, Y. J., and Saier, M. H. Jr. (2002). Overexpression of the Escherichia coli sugE gene confers resistance to a narrow range of quaternary ammonium compounds. J. Bacteriol. 184, 2543-2545. doi: 10.1128/JB.184.9.2543-2545. 2002

Dashti, Y., Grkovic, T., Abdelmohsen, U. R., Hentschel, U., and Quinn, R. J. (2014). Production of induced secondary metabolites by a coculture of sponge-associated actinomycetes, Actinokineospora sp. EG49 and Nocardiopsis sp. RV163. Mar. Drugs 12, 3046-3059. doi: 10.3390/md1205 3046

Dyke, K. G., Jevons, M. P., and Parker, M. T. (1966). Penicillinase production and intrinsic resistance to penicillins in Staphylococcus aureus. Lancet 1, 835-838. doi: 10.1016/S0140-6736(66)90182-6

Edgar, R., Domrachev, M., and Lash, A. E. (2002). Gene expression omnibus: NCBI gene expression and hybridization array data repository. Nucleic Acids Res. 30, 207-210. doi: 10.1093/nar/30.1.207

Fey, P. D., and Olson, M. E. (2010). Current concepts in biofilm formation of Staphylococcus epidermidis. Future Microbiol. 5, 917-933. doi: 10.2217/fmb. 10.56

Fitzgerald, J. R., Monday, S. R., Foster, T. J., Bohach, G. A., Hartigan, P. J., Meaney, W. J., et al. (2001). Characterization of a putative pathogenicity island from bovine Staphylococcus aureus encoding multiple superantigens. J. Bacteriol. 183, 63-70. doi: 10.1128/JB.183.1.63-70.2001

Flemming, H. C., and Wingender, J. (2010). The biofilm matrix. Nat. Rev. Microbiol. 8, 623-633. doi: 10.1038/nrmicro2415

Forstner, K. U., Vogel, J., and Sharma, C. M. (2014). READemption-a tool for the computational analysis of deep-sequencing-based transcriptome data. Bioinformatics 30, 3421-3423. doi: 10.1093/bioinformatics/btu533

Franca, A., Freitas, A. I., Henriques, A. F., and Cerca, N. (2012). Optimizing a qPCR gene expression quantification assay for S. epidermidis biofilms: a comparison between commercial kits and a customized protocol. PLoS One 7:e37480. doi: 10.1371/journal.pone.0037480

Franca, A., Perez-Cabezas, B., Correia, A., Pier, G. B., Cerca, N., and Vilanova, M. (2016). Staphylococcus epidermidis biofilm-released cells induce a prompt and more marked in vivo inflammatory-type response than planktonic or biofilm cells. Front. Microbiol. 7:1530. doi: 10.3389/fmicb.2016.01530

Freese, N. H., Norris, D. C., and Loraine, A. E. (2016). Integrated genome browser: visual analytics platform for genomics. Bioinformatics 32, 2089-2095. doi: 10. 1093/bioinformatics/btw069

Ge, X., Kitten, T., Chen, Z., Lee, S. P., Munro, C. L., and Xu, P. (2008). Identification of Streptococcus sanguinis genes required for biofilm formation and examination of their role in endocarditis virulence. Infect. Immun. 76, 2551-2559. doi: 10.1128/IAI.00338-08

Gerwick, W. H., and Moore, B. S. (2012). Lessons from the past and charting the future of marine natural products drug discovery and chemical biology. Chem. Biol. 19, 85-98. doi: 10.1016/j.chembiol.2011.12.014

Gibreel, T. M., and Upton, M. (2013). Synthetic epidermicin NI01 can protect Galleria mellonella larvae from infection with Staphylococcus aureus. J. Antimicrob. Chemother. 68, 2269-2273. doi: 10.1093/jac/ dkt195

Gomes, N. M., Bessa, L. J., Buttachon, S., Costa, P. M., Buaruang, J., Dethoup, T., et al. (2014). Antibacterial and antibiofilm activities of tryptoquivalines and meroditerpenes isolated from the marine-derived fungi Neosartorya paulistensis, $N$. laciniosa, $N$. tsunodae, and the soil fungi N. fischeri and N. siamensis. Mar. Drugs 12, 822-839. doi: 10.3390/md1202 0822

Hall-Stoodley, L., Costerton, J. W., and Stoodley, P. (2004). Bacterial biofilms: from the natural environment to infectious diseases. Nat. Rev. Microbiol. 2, 95-108. doi: $10.1038 /$ nrmicro821

Heilmann, C., Gerke, C., Perdreau-Remington, F., and Götz, F. (1996). Characterization of Tn917 insertion mutants of Staphylococcus epidermidis affected in biofilm formation. Infect. Immun. 64, 277-282.

Hoffmann, S., Otto, C., Kurtz, S., Sharma, C. M., Khaitovich, P., Vogel, J., et al. (2009). Fast mapping of short sequences with mismatches, insertions and deletions using index structures. PLoS Comput. Biol. 5:e1000502. doi: 10.1371/ journal.pcbi.1000502

Huber, W., and Koella, J. C. (1993). A comparison of three methods of estimating EC50 in studies of drug resistance of malaria parasites. Acta Trop. 55, 257-261. doi: 10.1016/0001-706X(93)90083-N

Indraningrat, A. A., Smidt, H., and Sipkema, D. (2016). Bioprospecting spongeassociated microbes for antimicrobial compounds. Mar. Drugs 14:E87. doi: $10.3390 / \mathrm{md} 14050087$

Kim, J. K., Jang, H. A., Won, Y. J., Kikuchi, Y., Han, S. H., Kim, C. H., et al. (2014a). Purine biosynthesis-deficient Burkholderia mutants are incapable of symbiotic accomodation in the stinkbug. ISME J. 8, 552-563. doi: 10.1038/ismej.20 13.168

Kim, J. K., Kwon, J. Y., Kim, S. Y., Han, S. H., Won, Y. J., Lee, J. H., et al. (2014b). Purine biosynthesis, biofilm formation, and persistence of an insect-microbe gut symbiosis. Appl. Environ. Microbiol. 80, 4374-4382. doi: 10.1128/AEM. 00739- 14

Kleinschmidt, S., Huygens, F., Faoagali, J., Rathnayake, I. U., and Hafner, L. M. (2015). Staphylococcus epidermidis as a cause of bacteremia. Future Microbiol. 10, 1859-1879. doi: $10.2217 /$ fmb. 15.98

Kodzius, R., and Gojobori, T. (2015). Marine metagenomics as a source for bioprospecting. Mar. Genomics 24(Pt 1), 21-30. doi: 10.1016/j.margen.2015.07. 001

Kong, C., Chee, C. F., Richter, K., Thomas, N., Abd Rahman, N., and Nathan, S. (2018). Suppression of Staphylococcus aureus biofilm formation and virulence by a benzimidazole derivative, UM-C162. Sci. Rep. 8:2758. doi: 10.1038/s41598018-21141-2

Kuroda, M., Ohta, T., Uchiyama, I., Baba, T., Yuzawa, H., Kobayashi, I., et al. (2001). Whole genome sequencing of methicillin-resistant Staphylococcus aureus. Lancet 357, 1225-1240. doi: 10.1016/S0140-6736(00)04403-2

Lage, H. (2003). ABC-transporters: implications on drug resistance from microorganisms to human cancers. Int. J. Antimicrob. Agents 22, 188-199. doi: 10.1016/S0924-8579(03)00203-6

Leary, J. T., Werger, M. M., Broach, W. H., Shaw, L. N., Santoni, B. G., Bernasek, T. L., et al. (2017). Complete eradication of biofilm from orthopedic materials. J. Arthroplasty 32, 2513-2518. doi: 10.1016/j.arth.2017.03.050

Lipinski, B., Hawiger, J., and Jeljaszewicz, J. (1967). Staphylococcal clumping with soluble fibrin monomer complexes. J. Exp. Med. 126, 979-988. doi: 10.1084/ jem.126.5.979 
Love, M. I., Huber, W., and Anders, S. (2014). Moderated estimation of fold change and dispersion for RNA-seq data with DESeq2. Genome Biol. 15:550. doi: 10.1186/s13059-014-0550-8

Mack, D., Davies, A. P., Harris, L. G., Rohde, H., Horstkotte, M. A., and Knobloch, J. K. (2007). Microbial interactions in Staphylococcus epidermidis biofilms. Anal. Bioanal. Chem. 387, 399-408. doi: 10.1007/s00216-006-0745-2

Mack, D., Siemssen, N., and Laufs, R. (1992). Parallel induction by glucose of adherence and a polysaccharide antigen specific for plastic-adherent Staphylococcus epidermidis: evidence for functional relation to intercellular adhesion. Infect Immun 60, 2048-2057.

Martin, M. (2011). Cutadapt removes adapter sequences from highthroughput sequencing reads. EMBnet J. 17, 10-12. doi: 10.14806/ej.17. 1.200

Martins, A., Vieira, H., Gaspar, H., and Santos, S. (2014). Marketed marine natural products in the pharmaceutical and cosmeceutical industries: tips for success. Mar. Drugs 12, 1066-1101. doi: 10.3390/md12021066

Mayer, A. M., Glaser, K. B., Cuevas, C., Jacobs, R. S., Kem, W., Little, R. D., et al. (2010). The odyssey of marine pharmaceuticals: a current pipeline perspective. Trends Pharmacol. Sci. 31, 255-265. doi: 10.1016/j.tips.2010. 02.005

McDougal, L. K., Steward, C. D., Killgore, G. E., Chaitram, J. M., Mcallister, S. K., and Tenover, F. C. (2003). Pulsed-field gel electrophoresis typing of oxacillinresistant Staphylococcus aureus isolates from the United States: establishing a national database. J. Clin. Microbiol. 41, 5113-5120. doi: 10.1128/JCM.41.11. 5113-5120.2003

Menzel, T. M., Tischer, M., Francois, P., Nickel, J., Schrenzel, J., Bruhn, H., et al. (2011). Mode of action of the novel bisquatenary bisnapthilimide MT02 against Staphylococcus aureus. Antimicrob. Agents Chemother. 55, 311-320. doi: 10. 1128/AAC.00586- 10

Namvar, A. E., Bastarahang, S., Abbasi, N., Ghehi, G. S., Farhadbakhtiarian, S., Arezi, P., et al. (2014). Clinical characteristics of Staphylococcus epidermidis: a systematic review. GMS Hyg. Infect. Control 9:Doc23. doi: 10.3205/dgkh0 00243

Nithya, C., Begum, M. F., and Pandian, S. K. (2010). Marine bacterial isolates inhibit biofilm formation and disrupt mature biofilms of Pseudomonas aeruginosa PAO1. Appl. Microbiol. Biotechnol. 88, 341-358. doi: 10.1007/ s00253-010-2777-y

Otto, M. (2009). Staphylococcus epidermidis-the 'accidental' pathogen. Nat. Rev. Microbiol. 7, 555-567. doi: 10.1038/nrmicro2182

Otto, M. (2012). Molecular basis of Staphylococcus epidermidis infections. Semin. Immunopathol. 34, 201-214. doi: 10.1007/s00281-011-0296-2

Palomo, S., Gonzalez, I., De La Cruz, M., Martin, J., Tormo, J. R., Anderson, M., et al. (2013). Sponge-derived Kocuria and Micrococcus spp. as sources of the new thiazolyl peptide antibiotic kocurin. Mar. Drugs 11, 1071-1086. doi: 10. 3390/md11041071

Percival, S. L., Hill, K. E., Malic, S., Thomas, D. W., and Williams, D. W. (2011). Antimicrobial tolerance and the significance of persister cells in recalcitrant chronic wound biofilms. Wound Repair Regen. 19, 1-9. doi: 10.1111/j.1524475X.2010.00651.x

Percival, S. L., Suleman, L., Vuotto, C., and Donelli, G. (2015). Healthcareassociated infections, medical devices and biofilms: risk, tolerance and control. J. Med. Microbiol. 64, 323-334. doi: 10.1099/jmm.0.00 0032

Putman, M., Van Veen, H. W., and Konings, W. N. (2000). Molecular properties of bacterial multidrug transporters. Microbiol. Mol. Biol. Rev. 64, 672-693. doi: 10.1128/MMBR.64.4.672-693.2000

Qin, N., Tan, X., Jiao, Y., Liu, L., Zhao, W., Yang, S., et al. (2014). RNA-Seq-based transcriptome analysis of methicillin-resistant Staphylococcus aureus biofilm inhibition by ursolic acid and reserveratrol. Sci. Rep. 4:5467. doi: 10.1038/ srep05467

Rahman, H., Austin, B., Mitchell, W. J., Morris, P. C., Jamieson, D. J., Adams, D. R., et al. (2010). Novel anti-infective compounds from marine bacteria. Mar. Drugs 8, 498-518. doi: $10.3390 / \mathrm{md} 8030498$

Rajput, A., Thakur, A., Sharma, S., and Kumar, M. (2018). aBiofilm: a resource of anti-biofilm agents and their potential implications in targeting antibiotic drug resistance. Nucleic Acids Res. 46, D894-D900. doi: 10.1093/nar/gkx 1157
Rosenstein, R., Nerz, C., Biswas, L., Resch, A., Raddatz, G., Schuster, S. C., et al. (2009). Genome analysis of the meat starter culture bacterium Staphylococcus carnosus TM300. Appl. Environ. Microbiol. 75, 811-822. doi: 10.1128/AEM. 01982-08

Ruisheng, A., and Grewal, P. S. (2011). purL gene expression affects biofilm formation and symbiotic persistence of Photorhabdus temperata in the nematode Heterorhabditis bacteriophora. Microbiology 157, 2595-2603. doi: 10. 1099/mic.0.048959-0

Sabate Bresco, M., Harris, L. G., Thompson, K., Stanic, B., Morgenstern, M., O'mahony, L., et al. (2017). Pathogenic mechanisms and host interactions in Staphylococcus epidermidis device-related infection. Front. Microbiol. 8:1401. doi: 10.3389/fmicb.2017.01401

Sakimura, T., Kajiyama, S., Adachi, S., Chiba, K., Yonekura, A., Tomita, M., et al. (2015). Biofilm-forming Staphylococcus epidermidis expressing vancomycin resistance early after adhesion to a metal surface. Biomed Res. Int. 2015:943056. doi: 10.1155/2015/943056

Shida, T., Koseki, H., Yoda, I., Horiuchi, H., Sakoda, H., and Osaki, M. (2013). Adherence ability of Staphylococcus epidermidis on prosthetic biomaterials: an in vitro study. Int. J. Nanomedicine 8, 3955-3961. doi: 10.2147/IJN. S51994

Sianglum, W., Srimanote, P., Taylor, P. W., Rosado, H., and Voravuthikunchai, S. P. (2012). Transcriptome analysis of responses to rhodomyrtone in methicillinresistant Staphylococcus aureus. PLoS One 7:e45744. doi: 10.1371/journal.pone. 0045744

Skaf, J., Hamarsheh, O., Berninger, M., Balasubramanian, S., Oelschlaeger, T. A., and Holzgrabe, U. (2017). Improving anti-trypanosomal activity of alkamides isolated from Achillea fragrantissima. Fitoterapia 125, 191-198. doi: 10.1016/j. fitote.2017.11.001

Stewart, P. S., and Costerton, J. W. (2001). Antibiotic resistance of bacteria in biofilms. Lancet 358, 135-138. doi: 10.1016/S0140-6736(01)05321-1

Stowe, S. D., Richards, J. J., Tucker, A. T., Thompson, R., Melander, C., and Cavanagh, J. (2011). Anti-biofilm compounds derived from marine sponges. Mar. Drugs 9, 2010-2035. doi: 10.3390/md9102010

Sun, W., Zhang, F., He, L., Karthik, L., and Li, Z. (2015). Actinomycetes from the South China Sea sponges: isolation, diversity, and potential for aromatic polyketides discovery. Front. Microbiol. 6:1048. doi: 10.3389/fmicb.2015. 01048

Thibane, V. S., Kock, J. L., Ells, R., Van Wyk, P. W., and Pohl, C. H. (2010). Effect of marine polyunsaturated fatty acids on biofilm formation of Candida albicans and Candida dubliniensis. Mar. Drugs 8, 2597-2604. doi: 10.3390/md81 02597

Thompson, C. C., Kruger, R. H., and Thompson, F. L. (2017). Unlocking marine biotechnology in the developing world. Trends Biotechnol. 35, 1119-1121. doi: 10.1016/j.tibtech.2017.08.005

Tsai, C. J., Loh, J. M., and Proft, T. (2016). Galleria mellonella infection models for the study of bacterial diseases and for antimicrobial drug testing. Virulence 7 , 214-229. doi: 10.1080/21505594.2015.1135289

Vinh, D. C., and Embil, J. M. (2005). Device-related infections: a review. J. Long Term Eff. Med. Implants 15, 467-488. doi: 10.1615/JLongTermEffMedImplants. v15.i5.20

Wang, J., Nong, X. H., Amin, M., and Qi, S. H. (2018). Hygrocin C from marinederived Streptomyces sp. SCSGAA 0027 inhibits biofilm formation in Bacillus amyloliquefaciens SCSGAB0082 isolated from South China Sea gorgonian. Appl. Microbiol. Biotechnol. 102, 1417-1427. doi: 10.1007/s00253-017-8672-z

Wermser, C., and Lopez, D. (2018). Identification of Staphylococcus aureus genes involved in the formation of structured macrocolonies. Microbiology 164, 801-815. doi: 10.1099/mic. 0.000660

WHO (2014). Antimicrobial Resistance: Global Report on Surveillance 2014. Geneva: WHO.

Widerstrom, M. (2016). Significance of Staphylococcus epidermidis in health care-associated infections, from contaminant to clinically relevant pathogen: this is a wake-up call! J. Clin. Microbiol. 54, 1679-1681. doi: 10.1128/JCM. 00743-16

Windolf, C. D., Logters, T., Scholz, M., Windolf, J., and Flohe, S. (2014). Lysostaphin-coated titan-implants preventing localized osteitis by Staphylococcus aureus in a mouse model. PLoS One 9:e115940. doi: 10.1371/journal.pone.0115940 
Xi, L., Ruan, J., and Huang, Y. (2012). Diversity and biosynthetic potential of culturable actinomycetes associated with marine sponges in the China seas. Int. J. Mol. Sci. 13, 5917-5932. doi: 10.3390/ijms1305 5917

Yoshioka, S., and Newell, P. D. (2016). Disruption of de novo purine biosynthesis in Pseudomonas fluorescens Pf0-1 leads to reduced biofilm formation and a reduction in cell size of surface-attached but not planktonic cells. PeerJ 4:e1543. doi: $10.7717 /$ peerj. 1543

Yu, G., Wang, L. G., Han, Y., and He, Q. Y. (2012). clusterProfiler: an R package for comparing biological themes among gene clusters. OMICS 16, 284-287. doi: $10.1089 /$ omi.2011.0118
Conflict of Interest Statement: The authors declare that the research was conducted in the absence of any commercial or financial relationships that could be construed as a potential conflict of interest.

Copyright (c) 2018 Balasubramanian, Skaf, Holzgrabe, Bharti, Förstner, Ziebuhr, Humeida, Abdelmohsen and Oelschlaeger. This is an open-access article distributed under the terms of the Creative Commons Attribution License (CC BY). The use, distribution or reproduction in other forums is permitted, provided the original author(s) and the copyright owner(s) are credited and that the original publication in this journal is cited, in accordance with accepted academic practice. No use, distribution or reproduction is permitted which does not comply with these terms. 